\title{
An idealized LES study of urban modification of moist convection
}

Article

Accepted Version

Zhu, X., Li, D., Zhou, W., Ni, G., Cong, Z. and Sun, T. (2017) An idealized LES study of urban modification of moist convection. Quarterly Journal of the Royal Meteorological Society, 143 (709). pp. 3228-3243. ISSN 1477-870X doi: https://doi.org/10.1002/qj.3176 Available at https://centaur.reading.ac.uk/73173/

It is advisable to refer to the publisher's version if you intend to cite from the work. See Guidance on citing.

To link to this article DOI: http://dx.doi.org/10.1002/qj.3176

Publisher: Royal Meteorological Society

All outputs in CentAUR are protected by Intellectual Property Rights law, including copyright law. Copyright and IPR is retained by the creators or other copyright holders. Terms and conditions for use of this material are defined in the End User Agreement.

\section{www.reading.ac.uk/centaur}

\section{CentAUR}

Central Archive at the University of Reading 
Reading's research outputs online 


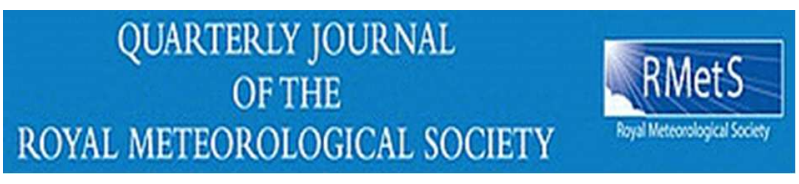

\section{An idealized LES study of urban modification of moist convection}

\begin{tabular}{|c|c|}
\hline Journal: & QJRMS \\
\hline Manuscript ID & QJ-17-0090.R1 \\
\hline Wiley - Manuscript type: & Research Article \\
\hline Date Submitted by the Author: & $\mathrm{n} / \mathrm{a}$ \\
\hline Complete List of Authors: & $\begin{array}{l}\text { Zhu, Xiaoliang; Tsinghua University, State Key Laboratory of Hydro- } \\
\text { Science and Engineering, Department of Hydraulic Engineering; Boston } \\
\text { University, Department of Earth and Environment } \\
\text { Li, Dan; Boston University, Department of Earth and Environment } \\
\text { Zhou, Wenyu; University of California San Diego Scripps Institution of } \\
\text { Oceanography } \\
\text { Ni, Guangheng ; Tsinghua University, State Key Laboratory of Hydro- } \\
\text { Science and Engineering, Department of Hydraulic Engineering } \\
\text { Cong, Zhentao; Tsinghua University, State Key Laboratory of Hydro- } \\
\text { Science and Engineering, Department of Hydraulic Engineering } \\
\text { Sun, Ting; Tsinghua University, State Key Laboratory of Hydro-Science and } \\
\text { Engineering, Department of Hydraulic Engineering; University of Reading, } \\
\text { Department of Meteorology }\end{array}$ \\
\hline Keywords: & Large-eddy simulation, Moist convection, Precipitation, Urban heat island \\
\hline Country Keywords: & China \\
\hline
\end{tabular}




\title{
An idealized LES study of urban modification of moist convection
}

\author{
Xiaoliang $\mathrm{Zhu}^{1,2}$, Dan $\mathrm{Li}^{2}$, Wenyu Zhou ${ }^{3}$, Guangheng $\mathrm{Ni}^{1}$, Zhentao Cong ${ }^{1}$, Ting Sun ${ }^{1,4^{*}}$ \\ 1: State Key Laboratory of Hydro-Science and Engineering, Department of Hydraulic Engineering, \\ Tsinghua University, Beijing 100084, China \\ 2: Department of Earth and Environment, Boston University, Boston, MA02215, USA \\ 3. Scripps Institution of Oceanography, University of California San Diego, La Jolla, California, USA. \\ 4. Department of Meteorology, University of Reading, Reading, UK
}

*Corresponding author: sunting@tsinghua.edu.cn

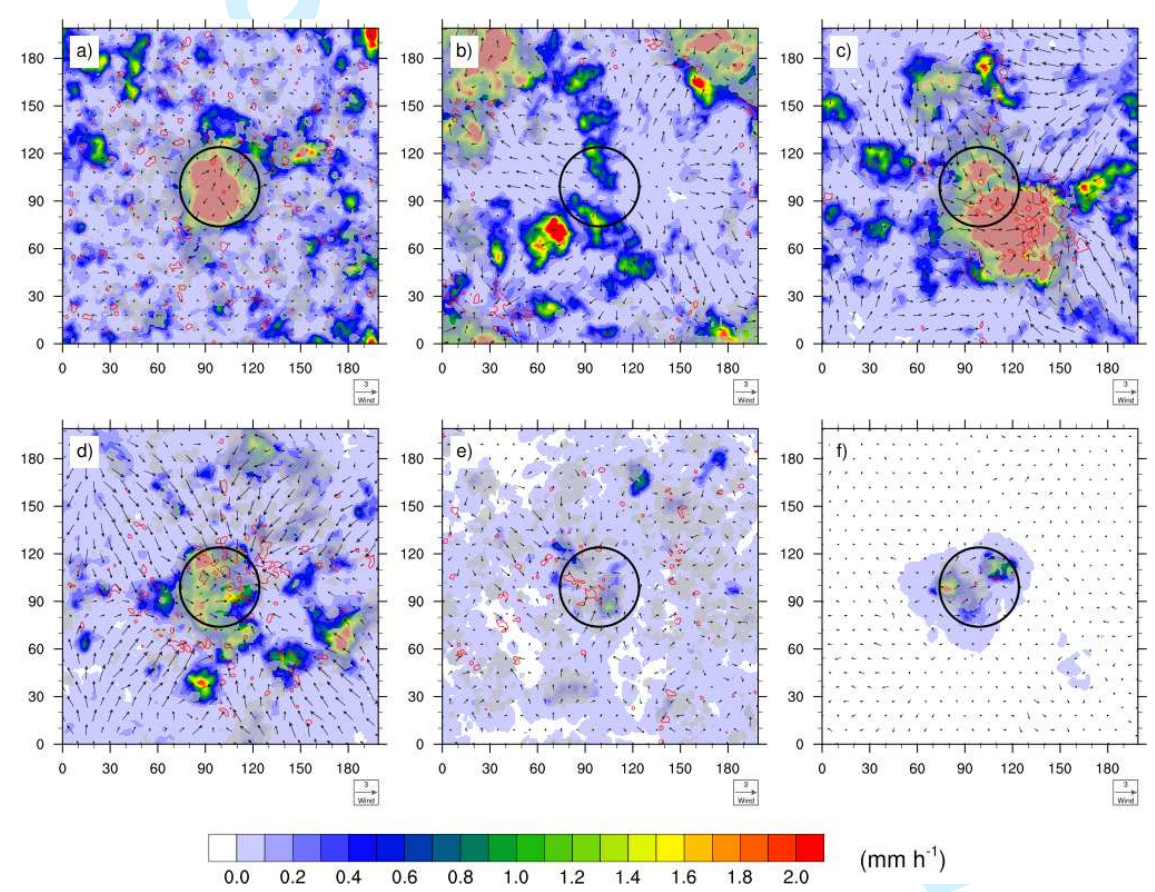

Spatial distributions of wind, cloud, and precipitation at different times.

- The impacts of urbanization on moist convection are investigated using a modified WRF-LES model.

- The existence of an urban island significantly enhances the rainfall rate over the urban area

- The urban rainfall rate increases linearly as the rural soil moisture increases while increases first and then decreases as the urban size increases 
1 An idealized LES study of urban modification of moist convection

2 Xiaoliang $\mathrm{Zhu}^{1,2}$, Dan $\mathrm{Li}^{2}$, Wenyu $\mathrm{Zhou}^{3}$, Guangheng $\mathrm{Ni}^{1}$, Zhentao Cong ${ }^{1}$, Ting

$3 \operatorname{Sun}^{1,4^{*}}$

4 1: State Key Laboratory of Hydro-Science and Engineering, Department of Hydraulic

5 Engineering, Tsinghua University, Beijing 100084, China

6 2: Department of Earth and Environment, Boston University, Boston, MA02215, USA

7 3. Scripps Institution of Oceanography, University of California San Diego, La Jolla,

8 California, USA.

9 4. Department of Meteorology, University of Reading, Reading, UK

$10 *$ Corresponding author: sunting@tsinghua.edu.cn 
12

13

\section{Abstract}

To understand the impacts of urbanization on moist convection, we explore how an idealized circular urban island affects the diurnal cycle and spatial distribution of rainfall over urban and surrounding rural areas at the diurnal equilibrium state using large-eddy simulations (LES) performed with the Weather Research and Forecasting (WRF) model. Compared to the control case where the whole domain is covered by grassland, the existence of an urban island significantly enhances the rainfall rate over the urban area as the stronger surface heating creates convergence zones and stronger vertical motions over the urban area. A suite of experiments is then conducted to investigate the effects of soil moisture of the surrounding rural land and the urban size on precipitation. Results show that as the rural soil moisture increases, both urban and rural precipitation rates increase almost linearly. This increase is not attributed to the urban heat island (UHI) effect but rather a stronger moisture deficit effect in the urban area creating a stronger moisture inflow. When the urban area becomes larger but the initial available water remains the same in the domain, the UHI effect and moisture deficit effect increase but the total water supply decreases. As a result, the urban rainfall rate increases first and then decreases as the urban size increases. This suggests that there is an 'optimal' scale at which the urban rainfall rate is maximized, at least in our modeling framework. Our simulations further suggest that this optimal scale occurs when the urban fraction lies between $1 \%$ and $10 \%$.

Key Word: Large-eddy simulation; Moist convection; Precipitation; Urban heat island; 


\section{Introduction}

With more than $50 \%$ of the global population now living in cities and continued urbanization, cities are becoming the nexus of water, energy, and health challenges facing the humanity in the $21^{\text {st }}$ century (Grimm et al., 2008; United Nations, 2014).

The continuous growth of urban population and the changing global climate mandate a better understanding of urban-atmosphere interactions within the context of climate change and variability. In response to this need, many studies have focused on the impact of urbanization on temperature, namely, the urban heat island effect (Oke, 1982; Arnfield, 2003). The factors contributing to the urban heat island (UHI) effect are relatively well understood nowadays, including reduced evapotranspiration due to abundant impervious surfaces, enhanced heat storage during daytime which is released at nighttime, and anthropogenic heat fluxes (Oke, 1982; Grimmond, 2007; Nie et al., 2014). However, the hydrometeorological impacts of urbanization remain elusive (Lowry, 1998; Shepherd, 2005; Mahmood et al., 2014).

The major challenges limiting our understanding of urban modification of convection is the difficulty in separating the urban signature from those of topography, land-sea or land-lake boundaries, and the large-scale atmospheric forcing in field experiments or in real-case modeling studies. As a result, studies conducted at different locations, in different seasons, and/or under different synoptic conditions often produce different findings. For example, the traditional paradigm generated by the famous METROpolitan Meteorological EXperiment (METROMEX) in the early 1970s (Changnon Jr et al., 1971; Changnon Jr, 1981) suggests that the precipitation rate in 
the downwind region of urban areas increases due to the enhanced vertical motion in urban areas. However, a recent modeling study by Schmid and Niyogi (2013) documented that in weak convection cases, urban regions can either suppress or invigorate rainfall over the downwind area. Trusilova et al. (2008) studied the impact of urbanization in Europe and found that replacing urban areas by grassland in a numerical model increases the rainfall amount in winter by an average value of 0.09 $\mathrm{mm}$ day $^{-1}$ but reduces the rainfall amount in summer by an average value of $-0.05 \mathrm{~mm}$ day $^{-1}$. Lei et al. (2008) simulated the 26 July 2005 heavy rainfall event over Mumbai, India and found that the city had a significant impact on the vertical wind structure with more precipitation occurring in the upwind region of Mumbai. However, Yang et al. (2014) investigated the 22-23 July 2010 heavy convective precipitation event in the Milwaukee, Wisconsin metropolitan region and concluded that urbanization had little effect on the vertical dynamics of precipitating cloud system. Many other similar studies have been conducted around the world as reviewed elsewhere (Shepherd, 2005; Pielke et al., 2011; Mahmood et al., 2014; Zhang et al., 2014; Yeung et al., 2015; Nie et al., 2017). All of these studies suggested strong connections between urban areas, convection enhancement, and increased precipitation. However, these experimental and modeling studies were unable to elucidate the fundamental mechanisms and pathways due to their consideration of all features in a fully interactive way.

Inspired by idealized modeling studies (Schlemmer et al., 2011; Schlemmer et al., 2012; Schmid and Niyogi, 2013) and the widely used Large Eddy Simulation (LES) technique (Moeng et al., 2007; Reinert and Wirth, 2009; Talbot et al., 2012; 
Yamaguchi and Feingold, 2012), we propose to use LES to perform controlled and quasi-idealized simulations to unravel the fundamental mechanisms through which urban surfaces initialize and modulate moist convection. The use of LES avoids the uncertainties from cumulus parameterizations by explicitly resolving moist convection and from planetary boundary layer parameterizations by explicitly resolving large turbulent eddies, respectively. As a logical starting point, we focus on the impacts of urban/rural characteristics and contrasts but do not consider the effects of large-scale forcing, topography and land-water boundaries. These complexities will be gradually and systematically added to the modeling system in forthcoming studies, thereby enabling a qualitative and quantitative understanding of interactions between urban/rural characteristics and other complexities in affecting moist convection.

Based on the idealized large-eddy simulations framework, we will also investigate how the effect of an urban island on moist convection is modulated by different soil moisture conditions in the surrounding rural areas. This is motivated by the rich literature on soil moisture-precipitation coupling, which has been debating in terms of positive feedback or negative feedback between soil moisture and precipitation (Betts et al., 1996; Eltahir, 1998; Hohenegger et al., 2009; Seneviratne et al., 2010; Taylor et al., 2012; Guillod et al., 2015; Tuttle and Salvucci, 2016). A recent study (Tuttle and Salvucci, 2016) presented empirical evidence of contrasting soil moisture-precipitation feedbacks across the United States and showed that the feedback is generally positive in the west and negative in the east, indicating the important role of regional aridity. This suggests that the background climate (thus the 
100

101

102

103

104

105

106

107

108

109

110

111

112

113

114

115

116

117

118

119

120

121

large-scale rural conditions in which cities are located) might play a role in the problem of urban modification on rainfall. In addition, another recent study by Guillod et al. (2015) showed that afternoon rainfall occurs preferentially over wetter areas in the mean sense but over drier areas if the terrain is heterogeneous. Their findings were based on remote-sensing data and have not been validated using process-based models. Our idealized LES modeling framework avoids the uncertainty from moist parameterization by explicitly resolving moist convection, and thus will be very useful for evaluating these results.

Besides the rural soil moisture, the influence of urban size is also investigated, which has important implications for understanding the impacts further urban growth on their local climate. Many previous studies have examined this issue but by simulating real-world cases. For example, Shepherd et al. (2010) found expanded areas of rainfall with the 2025 land-cover scenario in Houston. Schmid and Niyogi (2013) studied the magnitude of precipitation-modification potential of cities of different sizes under a particular synoptic condition and concluded that modification of rainfall increases linearly with the city size but such an increase became much slower when the city size is larger than $20 \mathrm{~km}$. However, this seems to be inconsistent with a recent radiative-convective equilibrium study on precipitation over tropical islands where precipitation over the island was found to increase with the size of island when the radius of the island is smaller than $20 \mathrm{~km}$ in a domain of $400 \mathrm{~km}$ by $400 \mathrm{~km}$. Once the island radius becomes larger than $20 \mathrm{~km}$, the precipitation starts to decrease (Cronin et al., 2015). The WRF-LES model introduced here is different from 
122 the models used in the studies just mentioned and hence is used to revisit this issue. It

123 is noted that the problem considered here is more complicated than the problem of

124 rainfall enhancement over tropical islands because the surrounding rural land in our

125 configuration, unlike the ocean, does not have an unlimited water supply.

126 The paper is organized as follows: Sect. 2 describes the configuration of the model

127 and numerical experiments; Sect. 3 analyzed and discussed the simulation results;

128 Sect. 4 presented the conclusions of our study.

\section{2.Method}

$130 \quad 2.1$ Model Description and Configuration

131 The numerical experiments are performed with the WRF-LES model (Moeng et

132 al., 2007; Talbot et al., 2012; Yamaguchi and Feingold, 2012). The WRF model is a

133 nonhydrostatic model based on fully compressible Euler equations. It has proven to be

134 a useful simulation tool to investigate convective PBL characteristics under

135 heterogeneous heating conditions (Liu et al., 2011; Kang and Lenschow, 2014). In a

136 previous study, we have made some necessary modifications in the WRF Version

137 3.5.1 to take into account the urban features (Zhu et al., 2016).

138 In all the simulations, the model is initialized with idealized potential temperature

139 and specific humidity profiles. The potential temperature is $300 \mathrm{~K}$ below $950 \mathrm{~m}$, and

140 there is a strong inversion layer of $50 \mathrm{~K} \mathrm{~km}^{-1}$ from 950 to $1050 \mathrm{~m}$. Above $1050 \mathrm{~m}$, the

141 potential temperature has a gradient of $3 \mathrm{~K} \mathrm{~km}^{-1}$. For the specific humidity, there is a

142 slightly decreasing trend from $6.00 \mathrm{~g} \mathrm{~kg}^{-1}$ at the ground surface to $5.8 \mathrm{~g} \mathrm{~kg}^{-1}$ at $950 \mathrm{~m}$

143 and a jump at the inversion layer to $2.0 \mathrm{~g} \mathrm{~kg}^{-1}$ in all the free atmosphere levels. 
144 Potential temperature fields in WRF-LES model are perturbed randomly at the first

145 four vertical layers to break the symmetry of the initial conditions. The model is 146 driven by periodic lateral boundary conditions in the horizontal directions and runs for 147 a sufficiently long period to achieve the diurnal equilibrium. Since no nudging is 148 performed, the initial profiles should not have any impacts on the final results.

149 We use the unified Noah land-surface model with four soil levels $(0.1 \mathrm{~m}, 0.3 \mathrm{~m}$, $150 \quad 0.6 \mathrm{~m}$ and $1 \mathrm{~m})$ to predict soil temperature and soil moisture. A small change we have 151 made is the treatment of runoff. Without treatment, the generated runoff leaves the 152 simulation domain and never comes back. The amount of runoff is very small in our 153 study due to the fact that no topography is considered, and has little effect on our 154 simulated results. To conserve water in the land surface, both surface runoff and 155 subsurface runoff generated over the previous time step is redistributed into the first 156 soil layer locally in the next time step. If the first layer is saturated, the remainder of 157 the water will be distributed into the next layer and so on. However, it should be noted that we do not deal with the runoff generated over the impervious surface in the urban area.

As for other physical schemes in WRF model, the 1.5 order turbulent kinetic energy scheme (Deardorff, 1980) is used to compute the subgrid-scale eddy viscosity and eddy diffusivity. WRF Single-Moment (WSM) 6-class (Hong and Lim, 2006) microphysics scheme, which is suitable for high-resolution simulations and can also take account of ice, snow and graupel processes, is utilized. The RRTM scheme (Mlawer et al., 1997) and Dudhia scheme (Dudhia, 1989) are chosen as the longwave 
166

167

168

169

170

171

172

173

174

175

176

177

178

179

180

181

182

183

184

185

186

187

radiation and the shortwave radiation scheme, respectively. The planetary boundary layer parameterization scheme is turned off since we use the LES mode. MM5 Monin-Obukhov scheme in the WRF model, which is based on the Monin-Obukhov Similarity Theory (MOST), is chosen as the surface layer scheme to determine exchange coefficients. The geostrophic wind is set to zero in our study and its influence is left for future investigations. The surface in the whole simulation domain is flat and the influence of topography is also left for future studies.

\subsection{Numerical experiments}

For all simulations, the domain size is $20 \mathrm{~km} \times 20 \mathrm{~km} \times 10 \mathrm{~km}$ along the $x, y$ and $z$ directions and is centered at the latitude of $38^{\circ} \mathrm{N}$. All simulations run for 30 days with a fixed diurnal cycle of incoming shortwave radiation at the top of the atmosphere (July 3, 2013). The resolution in both $\mathrm{x}$ - and $\mathrm{y}$-direction is $100 \mathrm{~m}$, while the vertical grid spacing varies with height from $32 \mathrm{~m}$ to $160 \mathrm{~m}$. A time step of $1 \mathrm{~s}$ is used. In the control case (case CTL), the land surface is covered by homogeneous grassland with the initial soil moisture 0.25 (volumetric, $\mathrm{m}^{3} \mathrm{~m}^{-3}$ ). The simulation characteristics in case CTL is shown in Table 1. To study urban modification of moist convection, we perform case URB with the same domain size as the control case but with a circular urban island with a diameter of $5 \mathrm{~km}$ located in the center of the domain. To parameterize urban land processes, the single-layer urban canopy model coupled into the Noah land surface model is turned on. The type of urban land in the cases URB is set to be high-intensity residential urban.

Besides the case URB, we also design several other cases shown in Table 2 to 
study the effects of soil moisture of the surrounding rural land and urban size. Cases starting with S (i.e., S0.2, S0.25, S0.3 and S0.35, where the number refers the initial soil moisture in units of $\mathrm{m}^{3} \mathrm{~m}^{-3}$ ) are designed to study the effect of soil moisture. Meanwhile, the wilting point is $0.066 \mathrm{~m}^{3} \mathrm{~m}^{-3}$ and the saturated value of soil moisture is $0.439 \mathrm{~m}^{3} \mathrm{~m}^{-3}$ in our study. In these cases, an urban island with same diameter of 5 $\mathrm{km}$ is located in the center of the domain, and the soil moisture is uniformly prescribed across all layers. Cases starting with D (i.e., D2.5, D5, D7.5 and D10, where the number refers to the diameter of the circular city in units of $\mathrm{km}$ and the initial soil moisture is $0.25 \mathrm{~m}^{3} \mathrm{~m}^{-3}$ ) are designed to study the effect of urban size. Due to the use of doubly periodic boundary conditions in our simulations, the urban areas are kept less than $20 \%$ of the domain to avoid the influence of upwind cities. To ensure identical initial available water amount in the domain as case D5, the initial soil moisture (ISM) in case D2.5, D7.5 and D10 are determined as:

$$
\mathrm{ISM}=\frac{\left\langle 0.25 \times\left(\mathrm{S}_{\text {domain }}-\mathrm{S}_{\text {urban }} \times \mathrm{FRC}_{\text {imp }}\right)\right\rangle_{\mathrm{D} 5}}{\left\langle\left(\mathrm{~S}_{\text {domain }}-\mathrm{S}_{\text {urban }}{ }^{*} \mathrm{FRC}_{\text {imp }}\right)\right\rangle_{\mathrm{D}}},
$$

where ISM is the initial soil moisture, $S_{\text {domain }}$ is the domain area $400 \mathrm{~km}^{2}, S_{\text {urban }}$ is the urban area and the $F R C_{\text {imp }}$ is the impervious surface fraction in urban grid ( 0.9 in our simulation). The angle brackets denote the value in different cases. Therefore, the initial soil moisture in case D2.5, D7.5 and D10 are 0.242, 0.265 and 0.290, respectively. In addition, we also perform a case with an urban diameter of $5 \mathrm{~km}$ in a $40 \mathrm{~km} \mathrm{x} 40 \mathrm{~km}$ domain (case D5L).

Before the numerical experiments were conducted, we first did several sensitivity cases (without an urban island) to investigate the sensitivity to both spatial resolutions 
209

210

211

212

213

214

215

216

217

218

219

220

221

222

223

224

225

226

227

228

229

230

and physical schemes using simulations of 2 weeks long. In particular, we tested the performance of the Smagorinsky subgrid scale scheme and the WSM 3-class microphysical scheme. To test the impact of the model resolution, we conducted three simulations with the horizontal resolution of $50 \mathrm{~m}$ and $200 \mathrm{~m}$, and 50 levels in the vertical direction, respectively. These sensitivity experiments are designed to understand the uncertainties in our CTL simulation and quantify the significance of the influence of urban areas. As they are not the central focus of our study, the results are presented in the appendix.

\section{Results and discussion}

\subsection{Characteristics of the diurnal equilibrium in the control simulation}

In this section, we describe the results of the control simulation with homogenous grassland surface. Fig. 1 to Fig. 4 show the results of temporal evolution, diurnal cycles, horizontal distributions, and vertical profiles, respectively.

Figure 1 shows the temporal evolution of domain averaged surface and atmospheric properties, including (a) sensible heat flux $\mathrm{H}$, (b) latent heat flux LE, (c) surface rainfall rate $\mathrm{P}$. It can be seen that the model gradually moves to a quasi-equilibrium state as the simulation develops and changes in daily averages of these variables become much slower and smaller (not shown). Turbulent heat fluxes (Fig. 1a and 1b) and rainfall rate (Fig. 1c) show clear diurnal cycles in the simulation. After the second week, the diurnal cycle of precipitation (Fig. 1c) starts to repeats itself from day to day, suggesting the onset of diurnal equilibrium convection as found in previous studies (Schlemmer et al., 2011; Schlemmer et al., 2012), which is loosely 
231

232

233

234

235

236

237

238

239

240

241

242

243

244

245

246

247

248

249

250

251

252

defined as the repeating pattern from day to day. Note that the whole land-atmosphere system here has not reached true equilibrium due to the long memory of soil moisture (Koster and Suarez, 2001; Rochetin et al., 2014). In the following, the average results from last 7 days are used in this study hereafter if not otherwise stated.

We then examine the average diurnal cycles of surface energy (Fig. 2a) and water balances (Fig. 2b). The surface net radiation (Fig. 2a, black line, Rn) is apparently affected by clouds (see for example the dip of Rn around 9:00 LST, local standard time ). The Bowen ratio ranges from 0.16 at the beginning of the day to 0.51 at noon and its average value is about 0.4 . These results are broadly consistent with observations over grasslands (Xu et al., 2002). The rain begins at 9:00 LST, peaks at 11:00 LST and comes to an end at 18:00 LST. For comparison, we define $\Delta \mathrm{S}>0$ as the reduction of soil moisture and it is clear from Fig. $2 \mathrm{~b}$ that before the rain starts evapotranspiration is balanced by the reduction of soil moisture. It is pointed out that a small amount of runoff is generated because sometimes the precipitation rate exceeds the infiltration capacity. To conserve the water, the generated runoff is captured and re-distributed into the soil instead of allowing it to leave the simulation domain. We note that this has little effect on the averaged results. In addition, we notice that the Noah land surface model and WRF does not impose a strict constringency on water conservation, and a small water imbalance is observed especially when a small time step (like $1 \mathrm{~s}$ used here) is used.

The diurnal cycles of convective available potential energy (CAPE) and convective inhibition $(\mathrm{CIN})$ are shown in Fig. 2c. CAPE reaches a peak exceeding 
253

254

255

256

257

258

259

260

261

262

263

264

265

266

267

268

269

270

271

272

273

274

$2350 \mathrm{~J} \mathrm{~kg}^{-1}$ at 8:00 LST right before it starts to rain. Almost at the same time, CIN reaches its minimum value of about $0.5 \mathrm{~J} \mathrm{~kg}^{-1}$ at 9:00 LST. Close inspection of the high frequency (1-min) outputs reveals that the rain begins at 8:40 LST. Fig. 2d illustrates the diurnal cycles of the lifting condensation level (LCL) and the planetary boundary layer (PBL) height. We compare these two variables because the PBL height exceeding the LCL is often viewed as a necessary condition for the onset of convective precipitation(Stull and Eloranta, 1984; Wilde et al., 1985; Haiden, 1997; Findell and Eltahir, 2003; Juang et al., 2007; Siqueira et al., 2009; Kang and Bryan, 2011; Santanello et al., 2011; Gentine et al., 2013; Yin et al., 2015). The PBL height is calculated using the potential temperature gradient method, where the thresholds for stable and unstable conditions are $1 \mathrm{~K} \mathrm{~km}^{-1}$ and $2 \mathrm{~K} \mathrm{~km}^{-1}$, respectively. As can be seen, although the domain averaged PBL height is always lower than LCL, the spatial variability of PBL height and LCL, indicated by the error bars, is significant, implying overlaps between PBL height and LCL in parts of the domain that may be inducible for convection.

Figure 3 shows the spatial distributions of wind, cloud, and precipitation right before (Fig. 3a), during (Fig. 3b), and after (Fig. 3c) the intensive rainfall period in the last day of the simulation. It can be seen that the convergence zones accompany the updraft regions (red line loops) where the upward wind speed is larger than $1.0 \mathrm{~m} \mathrm{~s}^{-1}$. Clouds mostly appear over these convergence areas, but precipitation only occurs adjacent to these convergence areas. At 9:00 LST, the rain event is at its early stage with small rainfall rates. At 11:00 LST, the convection is very strong covering a much 
275 larger area, and many organized updrafts appear. At 17:00 LST, clouds and updraft 276 regions are significantly reduced and little rain remains.

277 Figure 4 shows the domain averaged vertical profiles of potential temperature, 278 water vapor mixing ratio, relative humidity and winds. Distinct features of thermal 279 (Fig. 4a) and moist (Fig. 4a and 4b) conditions are observed between the atmospheric 280 boundary layer (the lower $1-2 \mathrm{~km}$ ) and the free atmosphere (above $2 \mathrm{~km}$ ). Over a 281 diurnal course, the profiles of potential temperature and water vapor mixing ratio in 282 the upper troposphere show minimal changes but those in the atmospheric boundary 283 layer have apparent diurnal cycles (not shown). In the daytime, the surface heating 284 destabilizes the atmospheric boundary layer and leads to convection. As there is no 285 geostrophic wind in our simulation, the horizontal wind speeds are on average close to 286 zero and their fluctuations are mainly controlled by the surface heating and cooling in 287 daytime and nighttime, respectively. Due to the use of periodic lateral boundary 288 conditions, the vertical wind speed (Fig. 4f) is always orders of magnitude smaller 289 than the horizontal wind speeds (Fig. 4d and 4e).

\subsection{Impacts of the existence of an urban island}

292

In this section, we present results from case URB, in which an urban island is created in the center of the domain, to study the impact of an urban island on moist convection. First of all, we note that the domain averaged diurnal cycles of the surface energy balance are similar between the default case and the case URB (Fig. 5a), due to the small fraction of the urban island. However, it can be seen from Fig. $5 \mathrm{~b}$ that the energy fluxes averaged value over the urban island are very different from those in the 
297

298

299

300

301

302

303

304

305

306

307

308

309

310

311

312

313

314

315

316

317

318

case URB. The surface net radiation in the urban area is smaller than the domain average value because of more rainfall and clouds over the urban area, which will be seen later. Even so, the sensible heat flux over urban areas in the case URB is much larger than the latent heat flux. This is because $90 \%$ of the urban island is impervious since the urban category is set to be high density residential as mentioned earlier. The higher sensible heat flux over urban areas can result in urban-rural circulations and stronger vertical motions over urban areas (not shown here but see e.g., Kang and Lenschow (2014)Zhang et al. (2014)Zhu et al. (2016)), which facilitate cloud formation and moist convection.

Figure 6 shows the vertical profiles of potential temperature, relative humidity, and cloud water mixing ratio of case CTL and case URB. It can be seen that there is no significant difference of the daily average profiles in terms of potential temperature, and relative humidity. The atmosphere over urban area shows slightly warmer and drier profiles over the urban area. But the profile of cloud water mixing ratio over the urban area in case URB is much larger. The diurnal cycles of cloud water mixing ratio and cloud cover fraction are examined in Fig. 7. Large fluctuations of cloud cover fraction over the urban area are observed in case URB. We note that the fluctuations become smoother but do not completely disappear when longer averaging periods are used. This might be related to feedbacks between clouds, shortwave radiation and surface sensible heat flux. As the cloud cover and rainfall rate are enhanced due to the higher sensible heat flux, the shortwave radiation in the urban area is reduced, which then reduces the surface temperature and weakens the urban-rural circulation and 
convective activities in the urban area.

Figure 8 a shows the domain averaged diurnal cycles of surface precipitation rate. Again, the domain averaged rainfall rates are similar between case CTL and URB (Fig. 8a). However, the average rainfall rate over the urban area is very different between the cases with an urban island (case URB) and the control case where there is no urban island. In particular, the rainfall rate $\left(6.32 \mathrm{~mm} \mathrm{day}^{-1}\right)$ over the urban area in the case URB is significantly larger than the rainfall rate $(2.08 \mathrm{~mm})$ in the control case. The surface precipitation rate also shows fluctuations over the diurnal cycle, and it seems that a period of 7 days is not sufficient to provide a smooth diurnal cycle of surface precipitation either. We also present the spatial distributions of surface precipitation at a few times on the last day (see red circles in Fig. 8b) in Fig. 9. It is clear that most of the precipitation concentrates over the urban area indicated by the black circle. Rain prefers to occur over the urban area not only when the rainfall rate is the largest but also at the beginning and the ending of the event. We have also calculated the averaged results over the last 3 days, 5 days 7 days, and 20 days and found that rain consistently prefers to occur over the urban area. This is consistent with the higher sensible heat flux in the urban area shown in Fig. 5, which results in the urban heat island circulation and strong vertical motions over urban areas (Fig. 9) and creates convergence zones in the urban area that facilitate convection. Previous studies also showed that clouds and rainfall tend to form sooner in the warmer area than the colder area (Kang and Bryan, 2011; Taylor et al., 2011; Guillod et al., 2015).

\subsection{Impacts of the rural soil moisture}


341 In this section, we examine the role of rural soil moisture in modulating the 342 impact of an urban island on convection. Figure 10 shows the mean surface 343 precipitation rates from four different cases in which the initial rural soil moisture 344 varies. Visually it is clear that the existence of an urban island in the domain always 345 leads to more rainfall in the urban area. The daily mean precipitation amounts range 346 from smaller than $0.01 \mathrm{~mm} \mathrm{~h}^{-1}$ in the rural area to larger than $1 \mathrm{~mm} \mathrm{~h}^{-1}$ in the urban 347 area.

348 Figure 11 provides further information about the scaling of changes in surface 349 precipitation with respect to changes in soil moisture. As can be seen from Fig. 11a, 350 the rainfall rates in all regions increase as the rural land becomes wetter. However, the 351 increase in the urban rainfall rate is much stronger. When normalized by the domain 352 average precipitation rate, the contrast between urban and rural becomes even stronger. 353 The normalized urban precipitation rate increases but the normalized rural 354 precipitation rate decreases nearly linearly as the rural soil moisture increases. Fig.11c 355 shows the total surface rainfall amounts normalized by the domain total rainfall 356 amount. As can be seen, despite that the precipitation rate is much higher in the urban 357 area, due to its small fraction, it still receives far less precipitation than the rural area. 358 Similar trends with increasing rural soil moisture are observed.

359 Fig.11 shows a strong positive relation between the rural land soil moisture and 360 the urban rainfall rate and amount, but a negative feedback in terms of 361 land-atmosphere coupling: the drier the urban area compared to the rural area, the 362 more rainfall it receives. The negative feedback is consistent with a recent study 
focusing on soil moisture-precipitation coupling over heterogeneous terrain (Guillod et al., 2015). To explore this further, the UHI effect and the moisture deficit effect are shown in Fig. 12 (Schmid and Niyogi, 2013). From Fig.12, The average UHI effect, defined as the difference in the $2 \mathrm{~m}$ potential temperature between the urban area and the rural area, are all higher than $1.0 \mathrm{~K}$. We see a decrease of UHI effects as the initial soil gets wetter. This is because stronger rain events occurring over the urban area reduce the net surface radiation (shown in Fig. 5b). This suggests that the UHI effect is not responsible for the increasing trend with rural soil moisture as seen in Fig. 11. The moisture deficit represented by the difference in the 2-m dew point temperature, on the other hand, becomes larger with increasing rural soil moisture. A stronger moisture deficit effect, namely, a stronger gradient in atmospheric water vapor, creates a stronger moisture flux into the urban area from the rural area, which enhances the in the rural area with a comparable surface precipitation rate and the maximum rainfall rate over urban area.

\subsection{Impacts of the urban size}

In order to investigate the role of the urban size, we describe the results of cases within different urban sizes in this section. The same initial soil moisture as the URB case and CTL case is used. Figure 13 shows the spatial distributions of surface precipitation rates in different cases (D2.5, D5, D7.5 and D10). Case D2.5 where the urban island only occupies $1 \%$ of the domain starts to show an enhancement of rainfall rate around the urban area. However, unlike other cases, there are still places 
385

386

387

388

389

390

391

392

393

394

395

396

397

398

399

400

401

402

403

404

405

406

expands, the rainfall concentrates more in the urban area and the rainfall rate becomes larger. For example, in cases D5 and D7.5 heavy rainfall rates are observed in urban areas. Interestingly, in the case D10, the rainfall rate in the urban area is much smaller than that in cases D5 and 7.5. This decrease is explained later.

When the rural area increases in the experiment while the urban area is maintained the same (c.f. Fig. 13b and 13e), the intensity of rainfall over urban area does not change much $\left(0.262 \mathrm{~mm} \mathrm{day}^{-1}\right.$ vs $\left.0.263 \mathrm{~mm} \mathrm{day}^{-1}\right)$, despite that the average rainfall rate over the domain increases from 0.076 to $0.1 \mathrm{~mm} \mathrm{day}^{-1}$ due to an enhanced water supply from a larger rural area.

To explain the results in Fig. 13, Fig. 14 shows the relation between surface precipitation and the urban island size. Specifically, Fig. 14a shows the rainfall rates averaged over different regions; Fig. 14b shows the urban/rural rainfall rates normalized by the domain averaged rainfall rate; Fig 14c shows the urban/rural total rainfall amounts normalized by the domain total rainfall amount; Fig 14d shows the relationship between the normalized rainfall rates and the total water amount supplied by the land surface. Comparing Fig. 14a and $14 \mathrm{c}$ shows that the trends in terms of rainfall rates and rainfall amounts become different since the size of urban area changes. As expected, the fraction of total rainfall amount received by the urban area is increased due to the growing size of urban area. The rainfall rate increases when the urban size increases from D2.5 to D5 but decreases with increasing urban size for urban sizes larger than D5. The large decrease in the urban rainfall rate in case D10 is because as the urban island expands (in case D10 the urban island occupies $20 \%$ of 
407 the domain), the water supply, which is almost entirely controlled by the rural area, is 408 reduced. It is important to point out that although we have ensured the same initial 409 available water in these cases, the total water supplied by the land surface still 410 decreases as urban area increases (Fig. 14d). This reduction in the water supply 411 becomes a more severe constraint on the urban rainfall rate, despite that the urban 412 area still produces larger sensible heating and stronger vertical motions. This suggests 413 that there exists an 'optimal' urban size, at least in this particular modeling framework, 414 at which the urban rainfall rate is maximized. The existence of an 'optimal' or 'critical' 415 size is consistent with previous study results (Schmid and Niyogi, 2013; Cronin et al., 416 2015), although the exact value is different due to the difference in the modeling 417 strategies. average UHI intensity increases from $1.17 \mathrm{~K}$ in case D2.5 to $1.61 \mathrm{~K}$ in case D10. On the other hand, the moisture deficit effect represented by the difference in the 2-m

421 dew point temperature also become stronger when the urban area increases due to the 422 enhanced rural soil moisture as the urban size increases. Considering changes in these 423 two factors (i.e., a larger UHI effect and a similar moisture deficit effect for a larger 424 urban island), one would think that the urban rainfall rate would be enhanced. 425 However, Fig. 14 shows that this only occurs when the urban size is smaller than a 426 threshold, after which the reduction in the total water supply becomes more important 427 and constrains the growth of urban rainfall rate.

\section{Conclusion}


In order to understand the impact of an urban island on precipitation, which is controlled by complex interactions between land and atmospheric processes, we develop an idealized framework using large eddy simulations within the Weather Research and Forecasting model. Using this idealized framework, we also study how the effects of an urban island on precipitation are modulated by different rural soil moisture and different urban island sizes.

The urban area significantly affects the surface energy balance. The sensible heat flux in the urban area is much larger than the rural area, resulting in urban heat island circulations and stronger vertical motions. These changes further have an important effect on the distribution of surface precipitation. Compared to the control case where the whole domain is covered by grassland, the existence of an urban island results in a significantly larger rainfall rate $\left(6.32 \mathrm{~mm}^{\text {day }^{-1}}\right.$ over urban area in case URB compared to $2.06 \mathrm{~mm}^{-1 a y}{ }^{-1}$ in case CTL).

The cases with increasing rural soil moisture show increases in the urban and rural precipitation rates. The increases are almost linear at least for the cases studied here. Although the UHI effects decrease as the rural soil moisture increases, most of the extra water supply from the wetter rural land is transported into the urban area. Under the influence of a stronger moisture deficit and thus a stronger moisture inflow, the urban precipitation rate and amount increase.

When the urban area gets larger but the initial available water remains the same, the UHI effect and the moisture deficit increases, but the water supply averaged over the whole simulation period decreases. This leads to an interesting phenomenon: as 
451 the urban size increases, the urban rainfall rate increases first and then decreases. This

452 suggests that there is an 'optimal' scale at which the urban rainfall rate is maximized, 453 at least in our modeling framework. Our simulations further suggest that this optimal 454 scale occurs when the urban fraction lies between $1 \%$ and $10 \%$ of the domain.

455 In conclusion, the study is the first step towards understanding the influence of 456 cities on moist convection in an idealized framework. This idealized framework offers 457 a new way to understanding interactions between urban islands and other 458 complexities such as the large-scale forcing, topography, and land-sea/land-lake 459 boundaries, which are not considered here but will be systematically included in 460 future investigations. In particular, because of the lack of large-scale forcing and the 461 long memory of soil, our simulations have not reached the radiative-convective 462 equilibrium. However, the changes from day to day are small enough to justify an 463 investigation of the behavior of the system. Our modeling framework can be also used 464 to study the broader research question of land-atmosphere coupling over 465 heterogeneous terrain.

466 Acknowledgements

467 This work was supported by NSFC (51679119 and 91647107), and by Open 468 Research Fund Program of State Key Laboratory of Hydroscience and Engineering 469 (sklhse-2015-A-02 and sklhse-2017-A-01). The simulations were performed on the 470 Tianhe-2 National Supercomputer Center in Guangzhou. XZ acknowledges the 471 support from the Tsinghua Scholarship for Overseas Graduate Studies. The data for 472 this paper are available through request to the corresponding author. 
473

474

475

476

477

478

479

480

481

482

483

484

485

486

487

488

489

490

491

492

493

494

\section{Appendix A}

\section{Sensitivity to physical schemes and spatial resolutions}

To investigate how physical schemes and domain resolutions affect our results, we use the Smagorinsky first order subgrid scale scheme in the case SGS and the WSM 3-class microphysical scheme in the case MP. To test the impact of the model resolution, we set the horizontal resolution $50 \mathrm{~m}$ in the case H50, $200 \mathrm{~m}$ in the case H200 and set 50 levels in the vertical direction in case V50. In all these sensitivity simulations, the land surface is homogeneous as in the CTL case. All these cases just run for 2 weeks and the average results from last 3 days are presented here.

Figure A1 shows the diurnal cycles of surface net radiation, surface sensible heat flux and latent heat flux. It can be seen from Fig. A1 that there are no significant differences between the sensitivity experiments and the control experiment. Case MP shows a slightly smaller surface net radiation than case CTL. Some fluctuations of net radiation are observed in the sensitivity cases with different horizontal/vertical resolutions around 9:00 LST. Clouds begin to form around this time (can be seen in Fig. 3a) and changing the model resolution appears to affect the formation and amount of clouds. The fluctuations in the net radiation result in small changes in the surface sensible heat flux and latent heat flux.

Figure A2 shows the domain averaged vertical profiles of potential temperature, water vapor mixing ratio and cloud water mixing ratio. It can be seen from Fig. A2a, $\mathrm{A} 2 \mathrm{~b}$ and A2c that there is no significant difference between case SGS and the control case where the only difference is the subgrid scale turbulence closure. However, 
changing the microphysical scheme (case MP) results in larger departures from the control simulation. In particular, using the WSM 3-class scheme in case MP generates a colder and drier atmosphere mainly because ice and snow processes are simplified in this scheme (Hong et al., 2004; Hong and Lim, 2006). The WSM 6-class scheme is suitable for high-resolution simulations and can also take account of ice, snow and graupel processes. Details of the advantages of the WSM 6-class scheme have been documented elsewhere (Hong and Lim, 2006). Regarding the influence of horizontal and vertical resolutions (Fig. A2d and A2e), a slightly colder and drier atmosphere is

503 observed with an increased horizontal resolution. Figure A2f shows the profiles of cloud water mixing ratio, and the cases with coarser resolutions have smaller values.

Figure A3 then examines diurnal cycles of cloud water mixing ratio and cloud cover fraction. We can see similar diurnal cycles of cloud cover fraction (i.e., the ratio of cloud coverage area to domain size) indicated by the solid black line and cloud water mixing ratio indicated by the shading across all cases but MP. With a colder and drier atmosphere generated in the case MP (Fig. A2a and A2b), the maximum cloud height is capped at $4 \mathrm{~km}$, which then reduces the total rainfall amount. Besides this, a higher cloud cover fraction in case MP is noticed. Due to the limitation of the maximum cloud height and cloud amount, most of shallow convection indicated by

513 the large could fraction over the domain do not develop into deep convection and 514 there is no more rain in case MP compared with case CTL (as will be seen in Fig. A6).

515 Coarse horizontal and vertical resolution both show smaller cloud water mixing ratio than case CTL, but the diurnal cycle and the cloud height are similar as the case CTL. 
517 We note that clouds in case V50 start to develop later than in the other cases (Fig A3c).

518 The delay of clouds and rainfall is probably related to the sensitivity of microphysical

519 scheme to the vertical resolution (Hong and Lim, 2006).

520 Figure A4 shows the resolved turbulent kinetic energy (TKE) and its three

521 components at 12:00 LST. The resolved TKE is defined as:

$$
\operatorname{TKE}=\frac{1}{2}\left(<u^{\prime} u^{\prime}>+<v^{\prime} v^{\prime}>+<w^{\prime} w^{\prime}>\right)
$$

522 where $u, v$ and $w$ are longitudinal, meridional and vertical velocities, respectively.

523 The angle brackets and primes denote plane averages and fluctuations, respectively.

524 Because the resolution is coarse near the top of domain and the TKE in the free

525 atmosphere should not be large, the profiles of TKE are only drawn from the ground

526 to the height of $2 \mathrm{~km}$ (Fig. A4). It can be seen that the average vertical profiles of

527 TKE and its three components are very similar among different cases. TKE near the

528 ground shows a relatively larger difference than the upper atmosphere. Then Fig. A5

529 examines diurnal cycles of TKE and its three components at a height of $200 \mathrm{~m}$. For

530 the diurnal cycles, it can be seen more clearly that the changes in the TKE are mostly

531 due to the horizontal components as $\left\langle w^{r} w^{r}\right\rangle$ is small. Case SGS shows a similar

532 diurnal cycle with case CTL. The subgrid scheme used in the case SGS is the

533 Smagorinsky scheme, which is different from the case CTL, and in principle may

534 alter the TKE below the subgrid scale. Since the TKE in Fig. A4 and A5 represent the

535 resolved TKE but not the subgrid scale TKE, it is clear that the subgrid scheme has

536 insignificant impacts on the resolved TKE. For the case MP, the different cloud

537 density and cloud cover fraction (Fig. A3c) reduce the net surface net radiation (Fig. 
538 A1a) and affect the development of TKE around noon (Fig. A5a). But the average 539 value (Fig. A4a) over the daytime is still close to case CTL.In terms of the effect of 540 resolutions, the vertical resolution has little impact on the TKE. We also notice 541 different amplitudes of the three components of TKE. The $<w^{t} w^{t}>$ in case H200 542 and case V50 show slightly smaller values, while it is slightly larger in case H50. The 543 differences among horizontal components are larger. The finest case H50 generates 544 the smallest TKE while cases H200 and CTL are more similar, suggesting a stronger 545 sensitivity to horizontal resolution than vertical resolution. This is consistent with 546 previous studies [Talbot et al. 2012].

Figure A6 shows the diurnal cycle of surface precipitation. In Fig. A1, the surface evapotranspiration rates are similar in these sensitivity cases, while the surface 549 precipitation has similar diurnal cycles but with different amplitudes. The daily average rainfall amounts of different cases are: $2.09 \mathrm{~mm} \mathrm{day}^{-1}$ (case CTL), $2.05 \mathrm{~mm}$ 551 day $^{-1}$ (case SGS), $1.83 \mathrm{~mm} \mathrm{day}^{-1}$ (case MP), $1.91 \mathrm{~mm}^{\text {day }}{ }^{-1}$ (case X50), $1.85 \mathrm{~mm} \mathrm{day}^{-1}$ 552 (case H200) and $1.65 \mathrm{~mm} \mathrm{day}^{-1}$ (case V50). Case V50 with a coarser vertical 553 resolution generates the smallest value. The beginning, the development and the end 554 of rainfall event are almost the same.

555 According to these sensitivity experiment results, it can be generalized that 556 different physical schemes and spatial resolutions have relatively small influences on 557 the surface energy balance and vertical profiles of domain averaged atmospheric 558 properties. The microphysical scheme seems to play a more important role in 559 controlling the cloud water distribution than the subgrid-scale turbulence closure and 
560 the grid resolution. The surface precipitation is more sensitive to the vertical

561 resolution than the horizontal resolution, whereas the resolved TKE is more sensitive

562 to the horizontal resolution than the vertical resolution.

563 
Arnfield AJ. 2003. Two decades of urban climate research: A review of turbulence, exchanges of energy and water, and the urban heat island. Int J Climatol, 23: 1-26. doi:10.1002/joc.859

Betts AK, Ball JH, Beljaars A, Miller MJ and Viterbo PA. 1996. The land surface $\square$ atmosphere interaction: A review based on observational and global modeling perspectives. J. Geophys. Res. Atmos., 101: 7209-7225. doi:10.1029/95JD02135

Changnon Jr SA (1981) Metromex: A Review and Summary. American Meteorological Society, Boston.

Changnon Jr SA, Huff FA and Semonin RG. 1971. METROMEX: An investigation of inadvertent $\begin{array}{llllll}\text { weather } & \text { modification. } & B & A m & \text { Meteorol } & \text { 95 }\end{array}$ doi:10.1175/1520-0477(1971)052<0958:MAIOIW>2.0.CO;2

Cronin TW, Emanuel KA and Molnar P. 2015. Island precipitation enhancement and the diurnal cycle in radiative-convective equilibrium. $Q J$ Roy Meteor Soc, 141: 1017-1034. doi:10.1002/qj.2443

Deardorff JW. 1980. Stratocumulus-capped mixed layers derived from a three-dimensional model. Bound-Lay Meteorol, 18: 495-527. doi:10.1007/BF00119502

Dudhia J. 1989. Numerical study of convection observed during the winter monsoon experiment using a mesoscale two-dimensional model. J Atmos Sci, 46: 3077-3107. doi:10.1175/1520-0469(1989)046<3077:NSOCOD $>2.0 . C O ; 2$

Eltahir EA. 1998. A soil moisture-rainfall feedback mechanism: 1. Theory and observations. Water Resour Res, 34: 765-776. doi:10.1029/97WR03499

Findell KL and Eltahir EAB. 2003. Atmospheric Controls on Soil Moisture-Boundary Layer Interactions. Part I: Framework Development. $J$ Hydrometeorol, 4: 552-569. doi:10.1175/1525-7541(2003)004<0552:ACOSML>2.0.CO;2

Gentine P, Holtslag AAM, D'Andrea F and Ek M. 2013. Surface and Atmospheric Controls on the Onset of Moist Convection over Land. $J$ Hydrometeorol, 14: 1443-1462. doi:10.1175/JHM-D-12-0137.1

Grimm NB, Faeth SH, Golubiewski NE, Redman CL, Wu J, Bai X and Briggs JM. 2008. Global change and the ecology of cities. Science, 319: 756-760. doi:10.1126/science.1150195

Grimmond S. 2007. Urbanization and global environmental change: local effects of urban warming. 
Guillod BP, Orlowsky B, Miralles DG, Teuling AJ and Seneviratne SI. 2015. Reconciling spatial and temporal soil moisture effects on afternoon rainfall. Nat Commun, 6. doi:10.1038/ncomms7443

Haiden T. 1997. An analytical study of cumulus onset. $Q J$ Roy Meteor Soc, 123: 1945-1960. doi:10.1002/qj.49712354309

Hohenegger C, Brockhaus P, Bretherton CS and Schaer C. 2009. The Soil Moisture-Precipitation Feedback in Simulations with Explicit and Parameterized Convection. J Climate, 22: 5003-5020. doi:10.1175/2009JCLI2604.1

Hong S and Lim JJ. 2006. The WRF Single-Moment 6-Class Microphysics Scheme (WSM6). Journal of the Korean Meteorological Society, 42: 129-151.

Hong SY, Dudhia J and Chen SH. 2004. A revised approach to ice microphysical processes for the bulk parameterization of clouds and precipitation. Mon Weather Rev, 132: 103-120. doi:10.1175/1520-0493(2004)132<0103:ARATIM>2.0.CO;2

Juang J, Porporato A, Stoy PC, Siqueira MS, Oishi AC, Detto M, Kim H and Katul GG. 2007. Hydrologic and atmospheric controls on initiation of convective precipitation events. Water Resour Res, 43. doi:10.1029/2006WR004954

Kang S and Bryan GH. 2011. A Large-Eddy Simulation Study of Moist Convection Initiation over Heterogeneous Surface Fluxes. Mon Weather Rev, 139. doi:10.1175/MWR-D-10-05037.1

Kang S and Lenschow DH. 2014. Temporal Evolution of Low-Level Winds Induced by Two-dimensional Mesoscale Surface Heat-Flux Heterogeneity. Bound-Lay Meteorol, 151: 501-529. doi:10.1007/s10546-014-9912-8

Koster RD and Suarez MJ. 2001. Soil Moisture Memory in Climate Models. J Hydrometeorol, 2 : 558-570. doi:10.1175/1525-7541(2001)002<0558:SMMICM>2.0.CO;2

Lei M, Niyogi D, Kishtawal C, Pielke RAS, Beltran-Przekurat A, Nobis TE and Vaidya SS. 2008. Effect of explicit urban land surface representation on the simulation of the 26 July 2005 heavy rain event over Mumbai, India. Atmos Chem Phys, 8: 5975-5995. doi:10.5194/acp-8-5975-2008

Liu G, Sun J and Yin L. 2011. Turbulence Characteristics of the Shear-Free Convective Boundary Layer Driven by Heterogeneous Surface Heating. Bound-Lay Meteorol, 140: 57-71. doi:10.1007/s10546-011-9591-7

Lowry WP. 1998. Urban effects on precipitation amount. Prog Phys Geog, 22: 477-520. 

doi:10.1177/030913339802200403

624

625

626

627

628

629

630

631

632

633

634

635

636

637

638

639

640

641

642

643

644

645

646

647

648

649

650

651

652

Mahmood R, Pielke RA, Hubbard KG, Niyogi D, Dirmeyer PA, McAlpine C, Carleton AM, Hale R, Gameda S and Beltrán Przekurat A. 2014. Land cover changes and their biogeophysical effects on climate. Int J Climatol, 34: 929-953. doi:10.1002/joc.3736

Mlawer EJ, Taubman SJ, Brown PD, Iacono MJ and Clough SA. 1997. Radiative transfer for inhomogeneous atmospheres: RRTM, a validated correlated-k model for the longwave. J. Geophys. Res. Atmos., 102: 16663-16682. doi:10.1029/97JD00237

Moeng C, Dudhia J, Klemp J and Sullivan P. 2007. Examining two-way grid nesting for large eddy simulation of the PBL using the WRF model. Mon Weather Rev, 135. doi:10.1002/joc.3736

Nie W, Sun T and Ni G. 2014. Spatiotemporal characteristics of anthropogenic heat in an urban environment: A case study of Tsinghua Campus. Build Environ, 82: 675-686. doi:10.1016/j.buildenv.2014.10.011

Nie W, Zaitchik BF, Ni G and Sun T. 2017. Impacts of Anthropogenic Heat on Summertime Rainfall in Beijing. J Hydrometeorol, 18: 693-712. doi:10.1175/JHM-D-16-0173.1

Oke TR. 1982. THE ENERGETIC BASIS OF THE URBAN HEAT-ISLAND. Q J Roy Meteor Soc, 108: 1-24. doi:10.1002/qj.49710845502

Pielke RA, Pitman A, Niyogi D, Mahmood R, McAlpine C, Hossain F, Goldewijk KK, Nair U, Betts R and Fall S. 2011. Land use/land cover changes and climate: modeling analysis and observational evidence. Wiley Interdisciplinary Reviews: Climate Change, 2: 828-850. doi:10.1002/wcc.144

Reinert D and Wirth V. 2009. A new large-eddy simulation model for simulating air flow and warm clouds above highly complex terrain. Part II: The moist model and its application to banner clouds. Bound-Lay Meteorol, 133: 113-136. doi:10.1007/s10546-009-9419-x

Rochetin N, Lintner BR, Findell KL, Sobel AH and Gentine P. 2014. Radiative-Convective Equilibrium over a Land Surface. J Climate, 27: 8611-8629. doi:10.1175/JCLI-D-13-00654.1

Santanello JA, Peters-Lidard CD and Kumar SV. 2011. Diagnosing the Sensitivity of Local LandAtmosphere Coupling via the Soil Moisture-Boundary Layer Interaction. J Hydrometeorol, 12: 766-786. doi:10.1175/JHM-D-10-05014.1

Schlemmer L, Hohenegger C, Schmidli J and Schär C. 2012. Diurnal equilibrium convection and land surface-atmosphere interactions in an idealized cloud $\square$ resolving model. Q J Roy Meteor Soc, 138: 1526-1539. doi:10.1002/qj.1892 
653

654

655

656

657

658

659

660

661

662

663

664

665

666

667

668

669

670

671

672

673

674

675

676

677

678

679

680

681

682

Schlemmer L, Hohenegger C, Schmidli J, Bretherton CS and Schaer C. 2011. An Idealized Cloud-Resolving Framework for the Study of Midlatitude Diurnal Convection over Land. J Atmos Sci, 68: 1041-1057. doi:10.1175/2010JAS3640.1

Schmid PE and Niyogi D. 2013. Impact of city size on precipitation-modifying potential. Geophys Res Lett, 40: 5263-5267. doi:10.1002/grl.50656

Seneviratne SI, Corti T, Davin EL, Hirschi M, Jaeger EB, Lehner I, Orlowsky B and Teuling AJ. 2010. Investigating soil moisture-climate interactions in a changing climate: A review. Earth-Sci Rev, 99: 125-161. doi:10.1016/j.earscirev.2010.02.004

Shepherd JM. 2005. A review of current investigations of urban-induced rainfall and recommendations for the future. Earth Interact, 9: 1-27. doi:10.1175/EI156.1

Shepherd JM, Carter M, Manyin M, Messen D and Burian S. 2010. The Impact of Urbanization on Current and Future Coastal Precipitation: A Case Study for Houston. Environment and Planning B: Planning and Design, 37: 284-304. doi:10.1068/b34102t

Siqueira M, Katul G and Porporato A. 2009. Soil Moisture Feedbacks on Convection Triggers: The Role of Soil-Plant Hydrodynamics. J Hydrometeorol, 10: 96-112. doi:10.1175/2008JHM1027.1

Stull RB and Eloranta EW. 1984. Boundary Layer Experiment-1983. B Am Meteorol Soc, 65: 450-456. doi:10.1175/1520-0477(1984)065<0450:BLE $>2.0 . \mathrm{CO} ; 2$

Talbot C, Bou-Zeid E and Smith J. 2012. Nested Mesoscale Large-Eddy Simulations with WRF: Performance in Real Test Cases. J Hydrometeorol, 13. doi:10.1175/JHM-D-11-048.1

Taylor CM, de Jeu RAM, Guichard F, Harris PP and Dorigo WA. 2012. Afternoon rain more likely over drier soils. Nature, 489: 423-426. doi:10.1038/nature11377

Taylor CM, Gounou A, Guichard F, Harris PP, Ellis RJ, Couvreux F and De Kauwe M. 2011. Frequency of Sahelian storm initiation enhanced over mesoscale soil-moisture patterns. Nat Geosci, 4: 430-433. doi:10.1038/ngeo1173

Trusilova K, Jung M, Churkina G, Karstens U, Heimann M and Claussen M. 2008. Urbanization Impacts on the Climate in Europe: Numerical Experiments by the PSU-NCAR Mesoscale Model (MM5). J Appl Meteorol Clim, 47: 1442-1455. doi:10.1175/2007JAMC1624.1

Tuttle S and Salvucci G. 2016. Empirical evidence of contrasting soil moisture-precipitation feedbacks across the United States. Science, 352: 825. doi:10.1126/science.aaa7185

United Nations DOEA. 2014. World Urbanization Prospects: the 2014 Revision, Highlights 
683

684

685

686

687

688

689

690

691

692

693

694

695

696

697

698

699

700

701

702

703

704

705

706

707

708

709

710

711
(ST/ESA/SER.A/352)..

Wilde NP, Stull RB and Eloranta EW. 1985. The LCL Zone and Cumulus Onset. Journal of Climate $\begin{array}{lll}\text { and } & \text { Applied } & \text { Meteorology, }\end{array}$ doi:10.1175/1520-0450(1985)024<0640:TLZACO >2.0.CO;2

Xu KM, Cederwall RT, Donner LJ, Grabowski WW, Guichard F, Johnson DE, Khairoutdinov M, Krueger SK, Petch JC, Randall DA, Seman CJ, Tao WK, Wang DH, Xie SC, Yio JJ and Zhang MH. 2002. An intercomparison of cloud-resolving models with the atmospheric radiation measurement summer 1997 intensive observation period data. $Q J$ Roy Meteor Soc, 128: 593-624. doi:10.1256/003590002321042117

Yamaguchi T and Feingold G. 2012. Technical note: Large $\square$ eddy simulation of cloudy boundary layer with the Advanced Research WRF model. J Adv Model Earth Sy, 4. doi:10.1029/2012MS000164

Yang L, Smith JA, Baeck ML, Bou-Zeid E, Jessup SM, Tian F and Hu H. 2014. Impact of Urbanization on Heavy Convective Precipitation under Strong Large-Scale Forcing: A Case Study over the Milwaukee-Lake Michigan Region. $J$ Hydrometeorol, 15: 261-278. doi:10.1175/JHM-D-13-020.1

Yeung JK, Smith JA, Baeck ML and Villarini G. 2015. Lagrangian Analyses of Rainfall Structure and Evolution for Organized Thunderstorm Systems in the Urban Corridor of the Northeastern United States. J Hydrometeorol, 16: 1575-1595. doi:10.1175/JHM-D-14-0095.1

Yin J, Albertson JD, Rigby JR and Porporato A. 2015. Land and atmospheric controls on initiation and intensity of moist convection: CAPE dynamics and LCL crossings. Water Resour Res, 51: 8476-8493. doi:10.1002/2015WR017286

Zhang N, Wang X and Peng Z. 2014. Large-Eddy Simulation of Mesoscale Circulations Forced by Inhomogeneous Urban Heat Island. Bound-Lay Meteorol, 151: 179-194. doi:10.1007/s10546-013-9879-x

Zhang Y, Smith JA, Luo L, Wang Z and Baeck ML. 2014. Urbanization and rainfall variability in the Beijing metropolitan region. J Hydrometeorol, 15: 2219-2235. doi:10.1175/JHM-D-13-0180.1

Zhu X, Ni G, Cong Z, Sun T and Li D. 2016. Impacts of surface heterogeneity on dry planetary boundary layers in an urban-rural setting. J. Geophys. Res. Atmos., 121: 12164-12179. doi:10.1002/2016JD024982 
1

2

3

4

5

6

7

8

9

10

11

12

13

14

15

16

17

18

19

20

21

22

23

24

25

26

27

28

29

30

31

32

33

34

35

36

37

38

39

40

41

42

43

44

45

46

47

48

49

50

51

52

53

54

55

56

57

58

59

60

712 
2

3

4

5

6

7

8

9

10

11

12

13

14

15

16

17

18

19

20

21

22

23

24

25

26

27

28

29

30

31

32

33

34

35

36

37

38

39

40

41

42

43

44

45

46

47

48

49

50

51

52

53

54

55

56

57

58

59

60

Table 1. Simulation characteristics

\begin{tabular}{ll}
\hline $\begin{array}{l}\text { Domain sizes } \\
\text { Resolutions }\end{array}$ & $20 \mathrm{~km}(\mathrm{x}), 20 \mathrm{~km}(\mathrm{y}), 10 \mathrm{~km}(\mathrm{z})$ \\
Time step & $1 \mathrm{~s}, 100 \mathrm{~m}(\mathrm{y}), 100$ levels $(\mathrm{z})$ \\
Simulation duration & 30 days \\
Microphysical scheme & WSM 6-class graupel \\
Eddy coefficient option & 1.5 order TKE closure \\
Long wave scheme & Rapid radiative transfer model \\
Short wave scheme & Dudhia scheme (38 ${ }^{\circ} \mathrm{N}$ at July 3$)$ \\
Surface layer scheme & MM5 Monin-Obukhov scheme \\
Land surface model scheme & Noah land surface model with single layer urban \\
\hline
\end{tabular}


Table 2. An overview of the experiment cases. ISM means the initial soil moisture and D means the diameter of the city. D5L means the case with an urban diameter of $5 \mathrm{~km}$ urban area in the larger domain $(40 \mathrm{~km} \times 40 \mathrm{~km})$.

\begin{tabular}{lcccc}
\hline Case Name & $\begin{array}{c}\text { Feature } \\
\text { ISM }\left(\mathrm{m}^{3} \mathrm{~m}^{-3}\right)\end{array}$ & Case Name & $\mathrm{D}(\mathrm{km})$ & ISM $\left(\mathrm{m}^{3} \mathrm{~m}^{-3}\right)$ \\
\hline S0.2 & 0.2 & $\mathrm{D} 2.5$ & 2.5 & 0.242 \\
$\mathrm{~S} 0.25$ & 0.25 & $\mathrm{D} 5 / \mathrm{D} 5 \mathrm{~L}$ & 5 & 0.25 \\
$\mathrm{~S} 0.3$ & 0.3 & $\mathrm{D} 7.5$ & 7.5 & 0.265 \\
$\mathrm{~S} 0.35$ & 0.35 & $\mathrm{D} 10$ & 10 & 0.290 \\
\hline
\end{tabular}



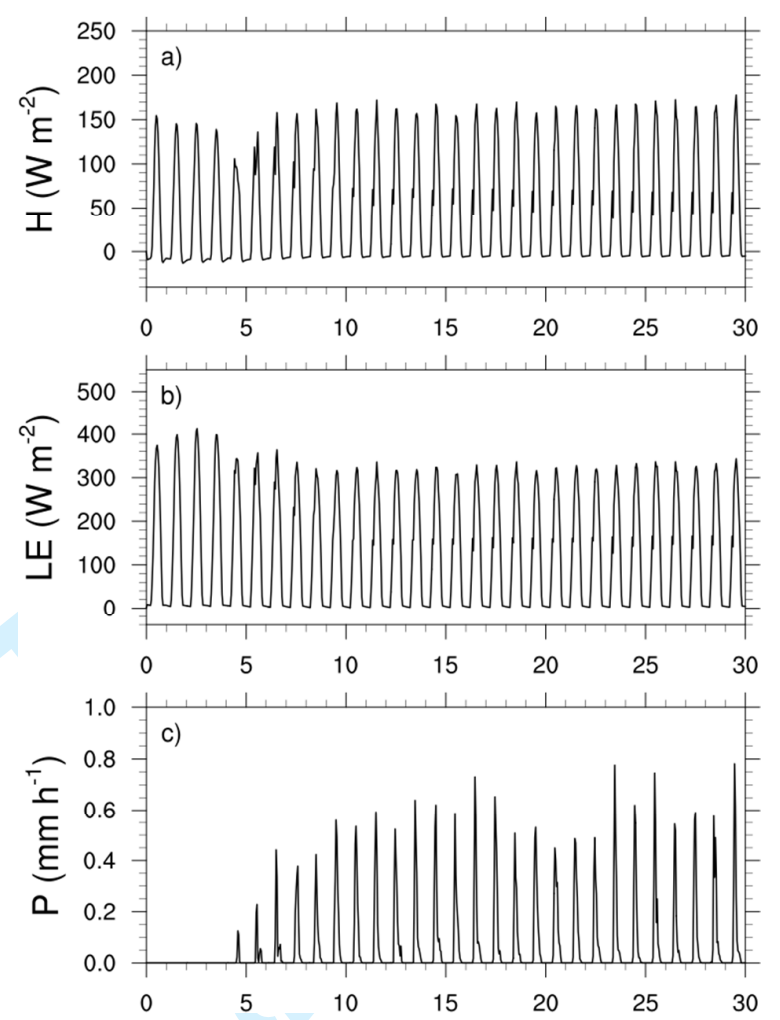

Figure 1. The temporal evolution of domain averaged (a) sensible heat flux $H(W$

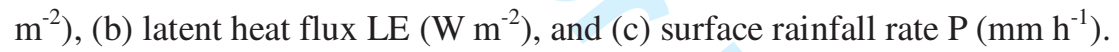



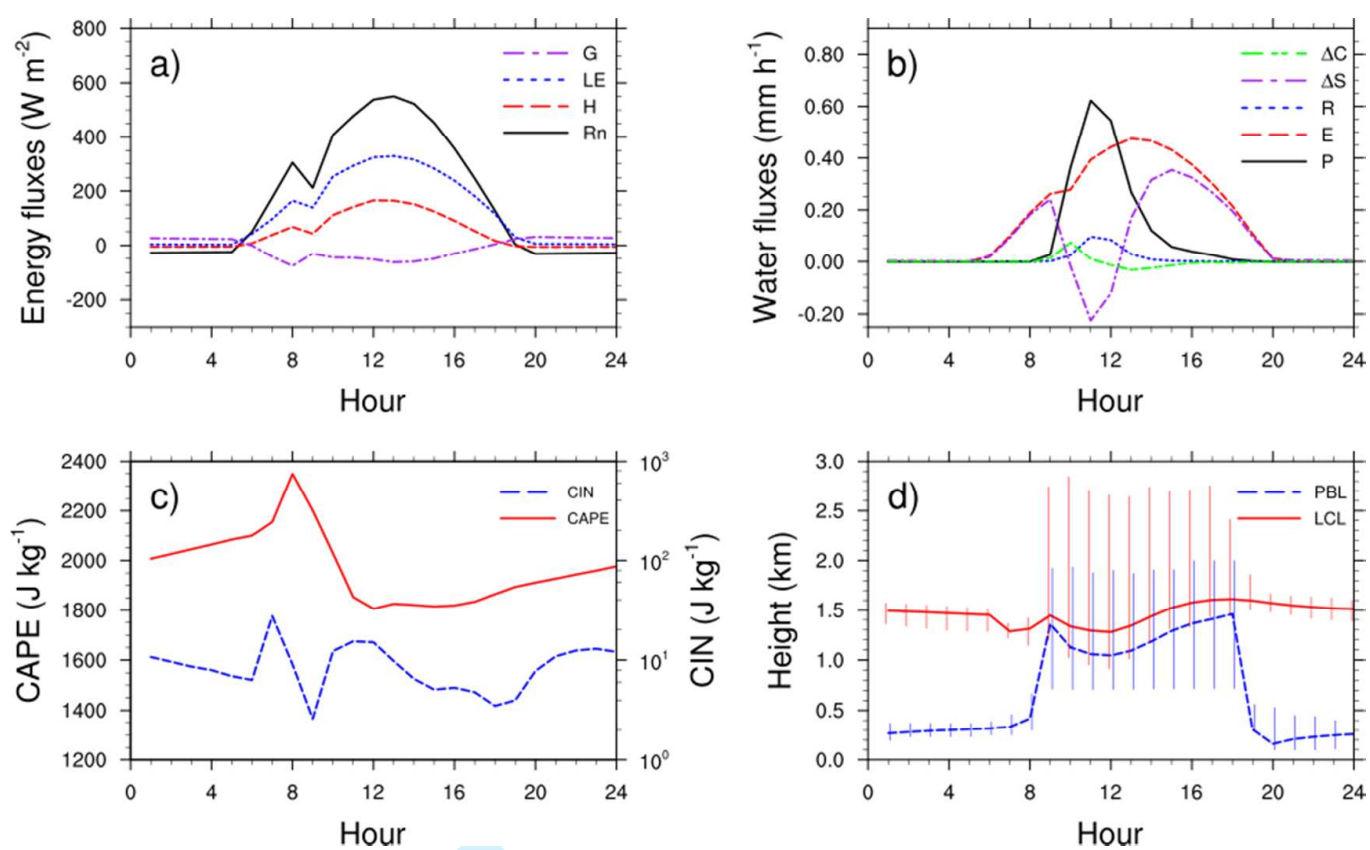

Figure.2 The average diurnal cycles of (a) energy fluxes: surface net radiation (Rn, black line), surface sensible heat flux (H, red line), surface latent heat flux (LE, blue line) and ground heat flux ( $\mathrm{G}$, purple line, positive towards up) ( $\left.\mathrm{W} \mathrm{m}^{-2}\right)$; (b) water fluxes: surface precipitation rate (P, black line), surface evapotranspiration (E, red line), surface runoff ( $R$, blue line), the change of soil moisture ( $\Delta S$, purple line) and the change of canopy water $\left(\Delta \mathrm{C}\right.$, green line) $\left(\mathrm{mm} \mathrm{h}^{-1}\right)$; (c) convective available potential energy CAPE and convective inhibition CIN $\left(\mathrm{J} \mathrm{kg}^{-1}\right)$; (d) the domain average height of lifted condensation level LCL (solid line) and planetary boundary layer PBL (dashed line) (km). The vertical bars in (d) indicate the range of LCL and PBL. 

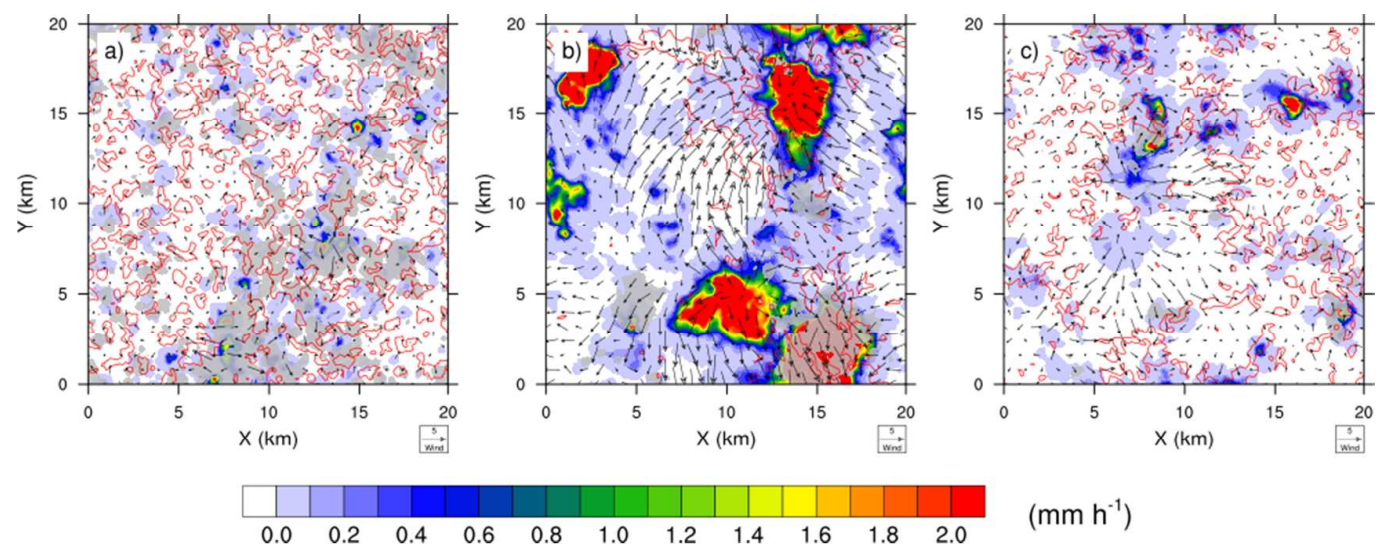

Figure. 3 Spatial distributions of wind, cloud, and precipitation at (a) 09:00 LST, (b) 11:00 and (c) 17:00.. The colored shading indicates the precipitation $\left(\mathrm{mm} \mathrm{h}^{-1}\right)$. The gray shading is the cloud water mixing ratio where the column integrated values larger than $0.01 \mathrm{~g} \mathrm{~kg}^{-1}$ are displayed. The red contour lines indicate upward velocity larger than $1.0 \mathrm{~m} \mathrm{~s}^{-1}$ at $700 \mathrm{~m}$, and the black arrows are horizontal winds at $160 \mathrm{~m}$. 

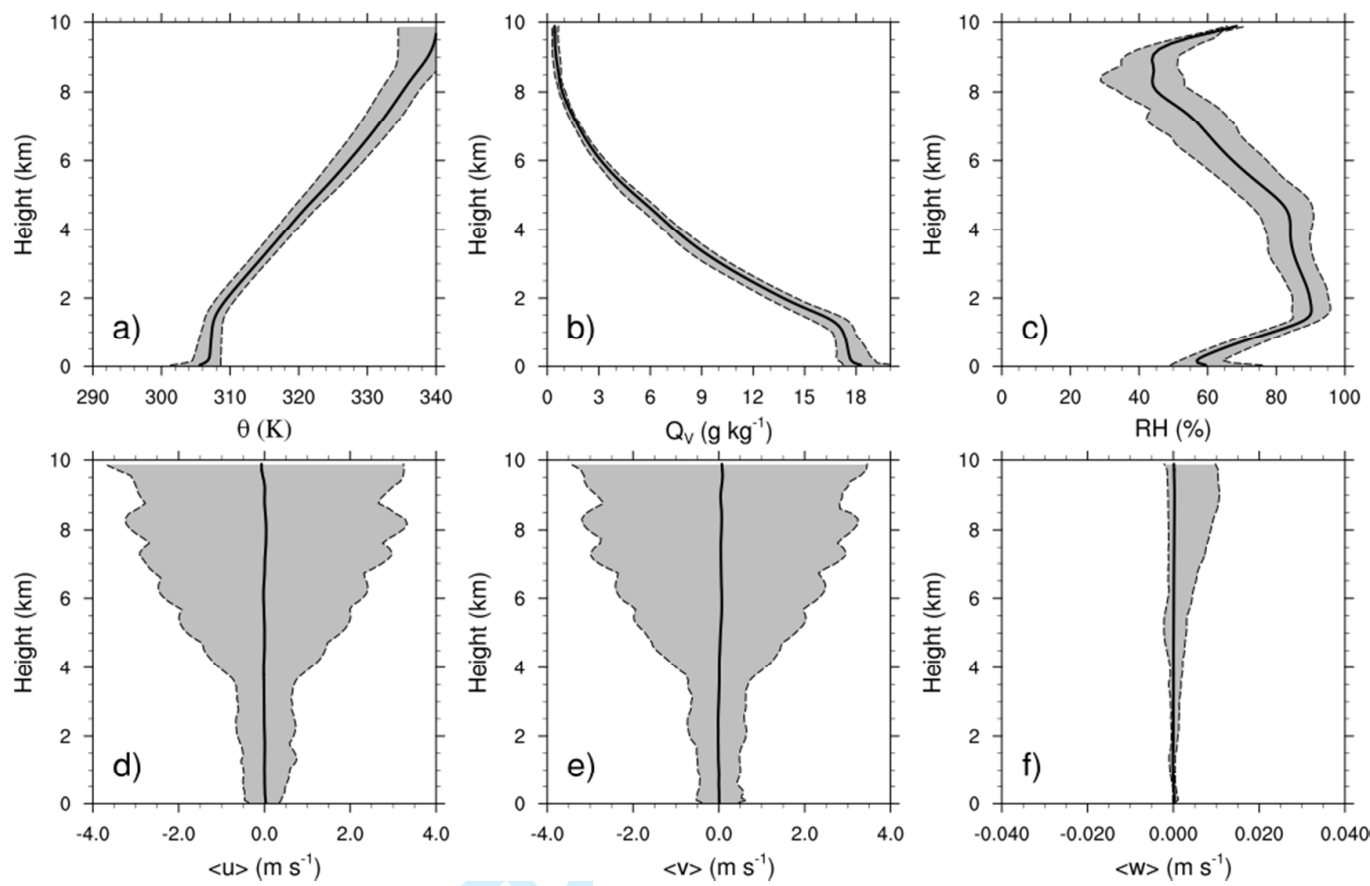

Figure 4. Profiles of (a) potential temperature (K), (b) water vapor mixing ratio (g $\left.\mathrm{kg}^{-1}\right)$, (c) relative humidity (\%), (d) longitudinal wind $\left(\mathrm{m} \mathrm{s}^{-1}\right)$, (e) meridional wind $\left(\mathrm{m} \mathrm{s}^{-1}\right)$ and (f) vertical wind $\left(\mathrm{m} \mathrm{s}^{-1}\right)$. The black lines show the averaged profiles in the last three days, and the shadow areas show the range of hourly profiles. 
2
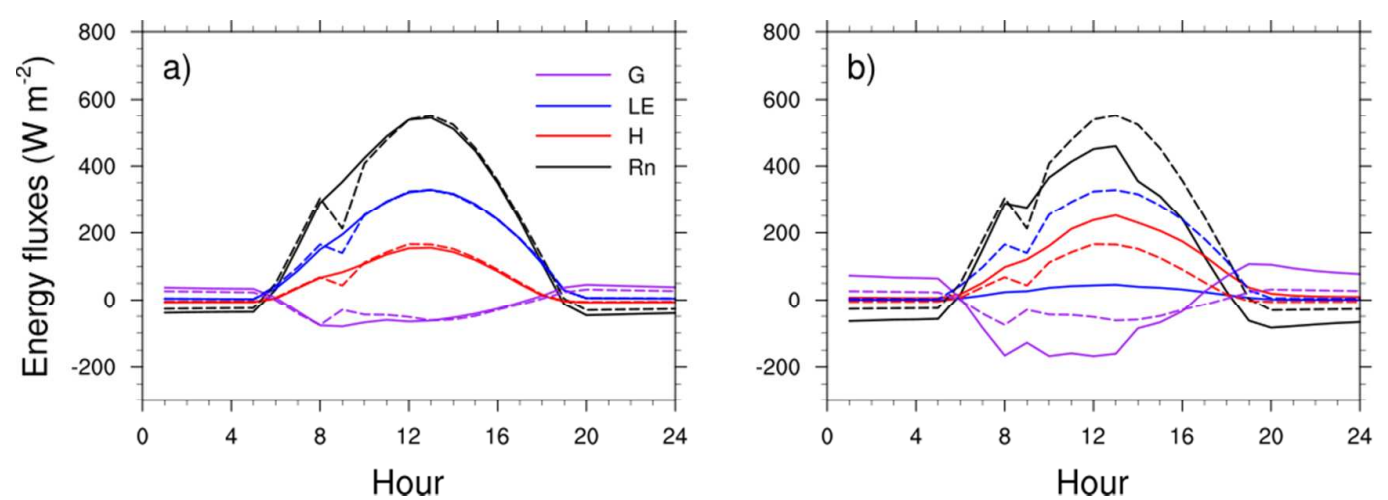

Figure 5. The averaged diurnal cycle of the surface energy balance (a) average values over the whole domain; (b) average values over the urban area for case URB. The solid lines and dashed lines are the energy fluxes in the case URB and case CTL, respectively. 

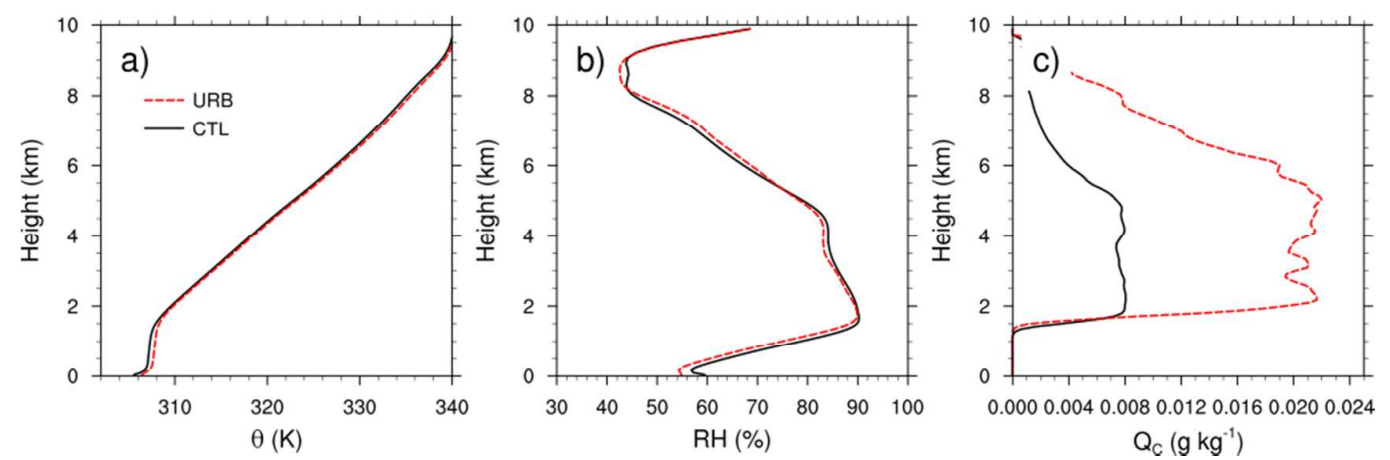

Figure 6. Vertical profiles of (a) potential temperature $(\mathrm{K})$, (b) relative humidity (\%), and (c) cloud water mixing ratio $\left(\mathrm{g} \mathrm{kg}^{-1}\right)$. The values of case URB are averaged over the urban area. 

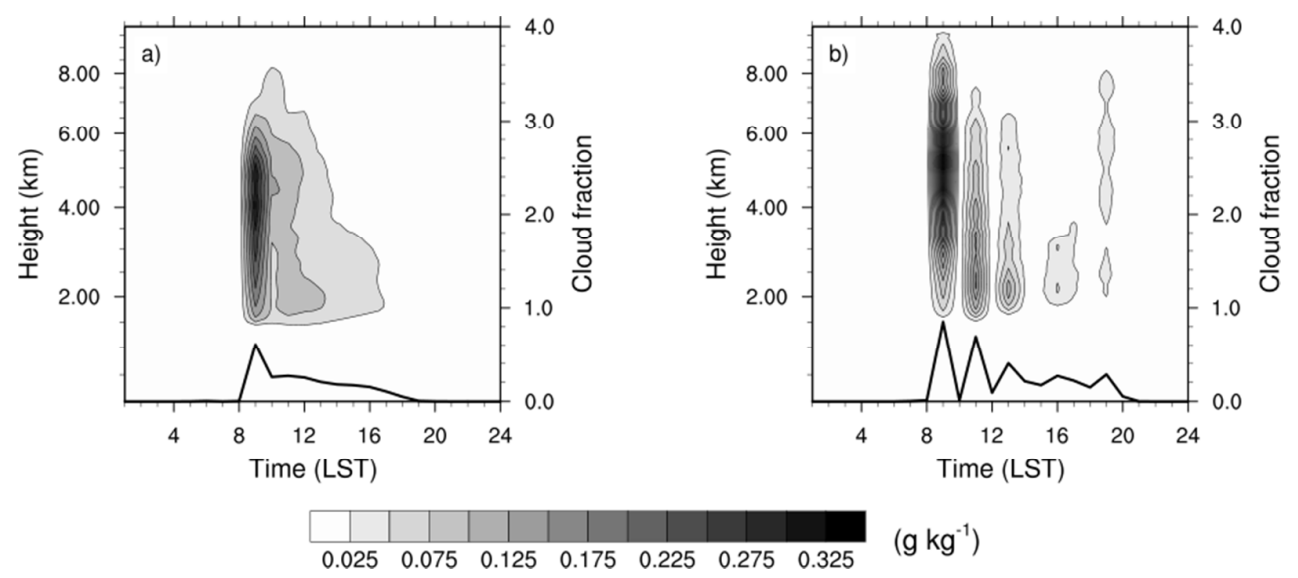

Figure 7. The diurnal cycles of cloud water mixing ratio $\left(\mathrm{g} \mathrm{kg}^{-1}\right.$, shaded area) and cloud cover fraction (solid black line) for cases (a) CTL and (b) URB. The values of case URB are averaged over the urban area. Note that the $y$-axis is not equidistant as the WRF model uses eta levels in the vertical direction. 

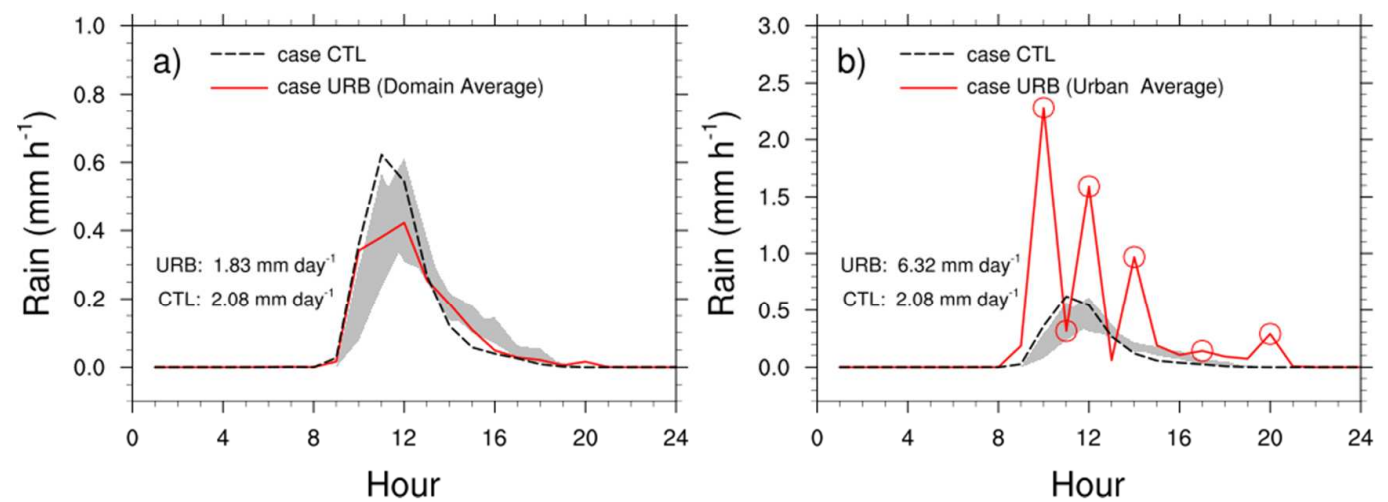

Figure 8. The diurnal cycles of the surface precipitation rate (a) averaged over the whole domain; (b) averaged over the urban area for case URB. Note the change in the range of y-axis between (a) and (b). The red solid lines and black dash lines are the rainfall rate in the case URB and case CTL. The shaded area indicates the range of rainfall rates in sensitivity cases presented in the Appendix. The red marker in Fig. $8 \mathrm{~b}$ indicates the times at which horizontal distributions of surface precipitation are shown in Fig.9. 

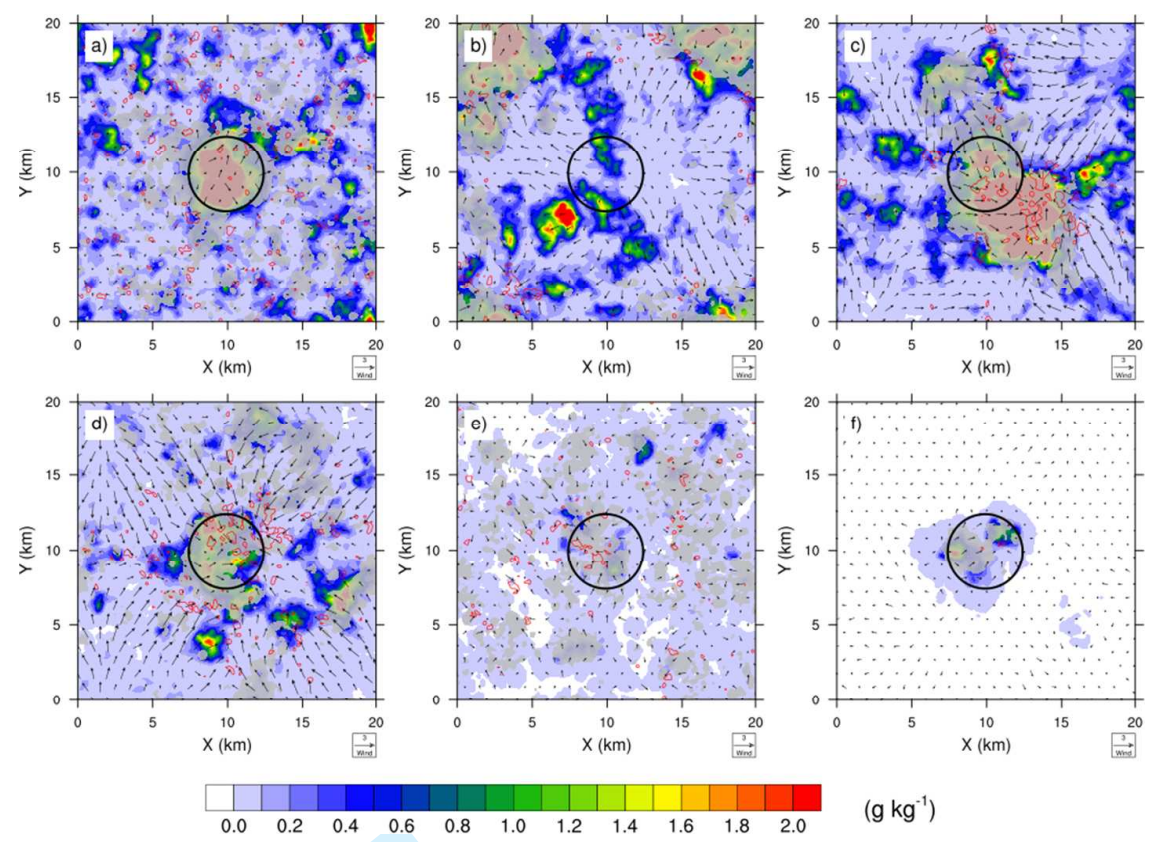

Figure 9. Same as Fig. 3 but for case URB. (a), (b), (c), (d), (e) and (f) are results at 10:00, 11:00, 12:00, 14:00, 17:00 and 20:00, respectively. These times are marked by red cycles in Fig. 8b accordingly. 

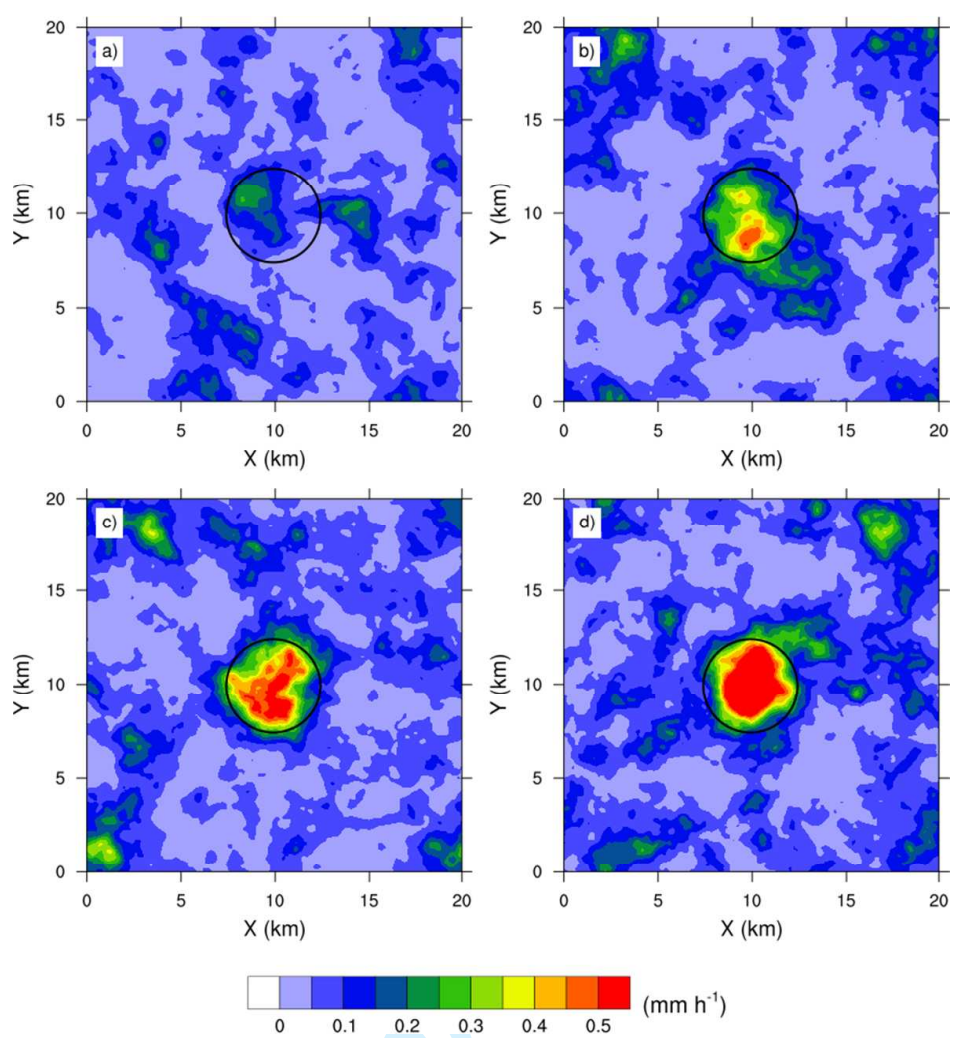

Figure 10. Surface precipitation rates averaged over last seven days from (a) case S0.2; (b) case S0.25; (c) case S0.3; and (d) case S0.35. The black cycle denotes the urban area. 
2
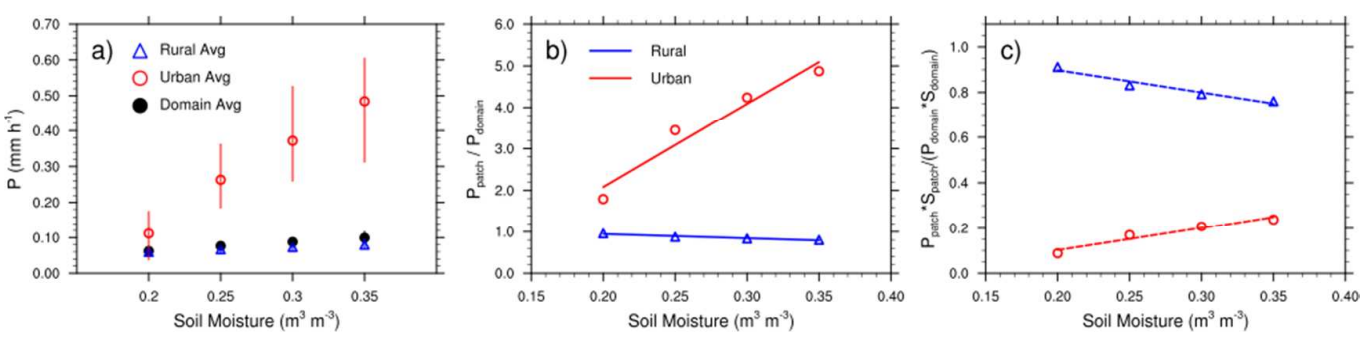

Figure 11. (a) The surface precipitation rates average over different regions. (b) The urban/rural surface precipitation rates normalized by the domain averaged precipitation rate. (c) The urban/rural total rainfall amount normalized by the total rainfall amount over the whole domain. The error bars in Fig. 11a indicate the range of rainfall rates. 


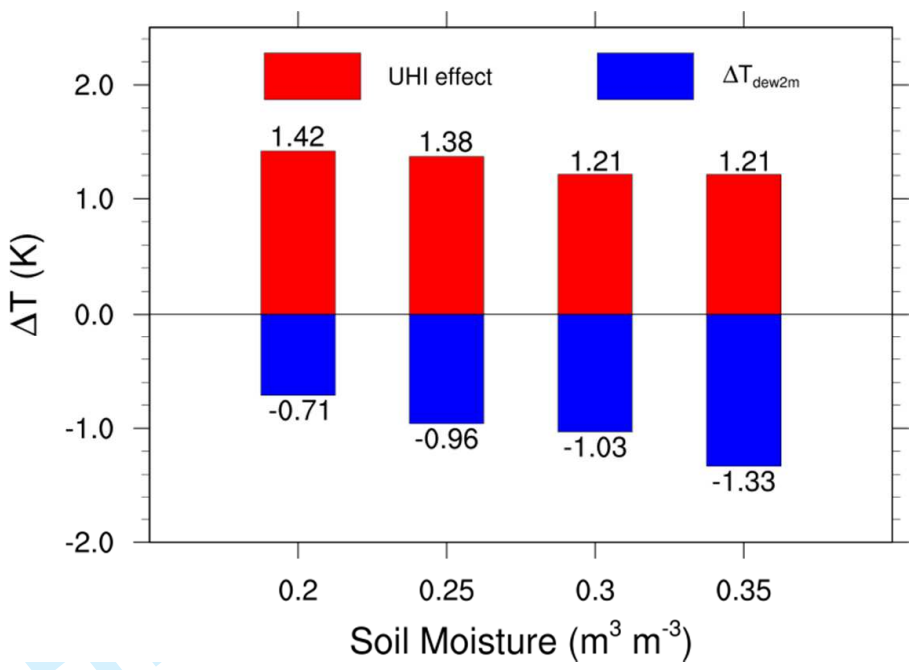

Figure 12. The average urban heat island effect (the difference in potential temperature at $2 \mathrm{~m}$ height) and moisture deficit effect (the difference in dew point temperature at $2 \mathrm{~m}$ height) 

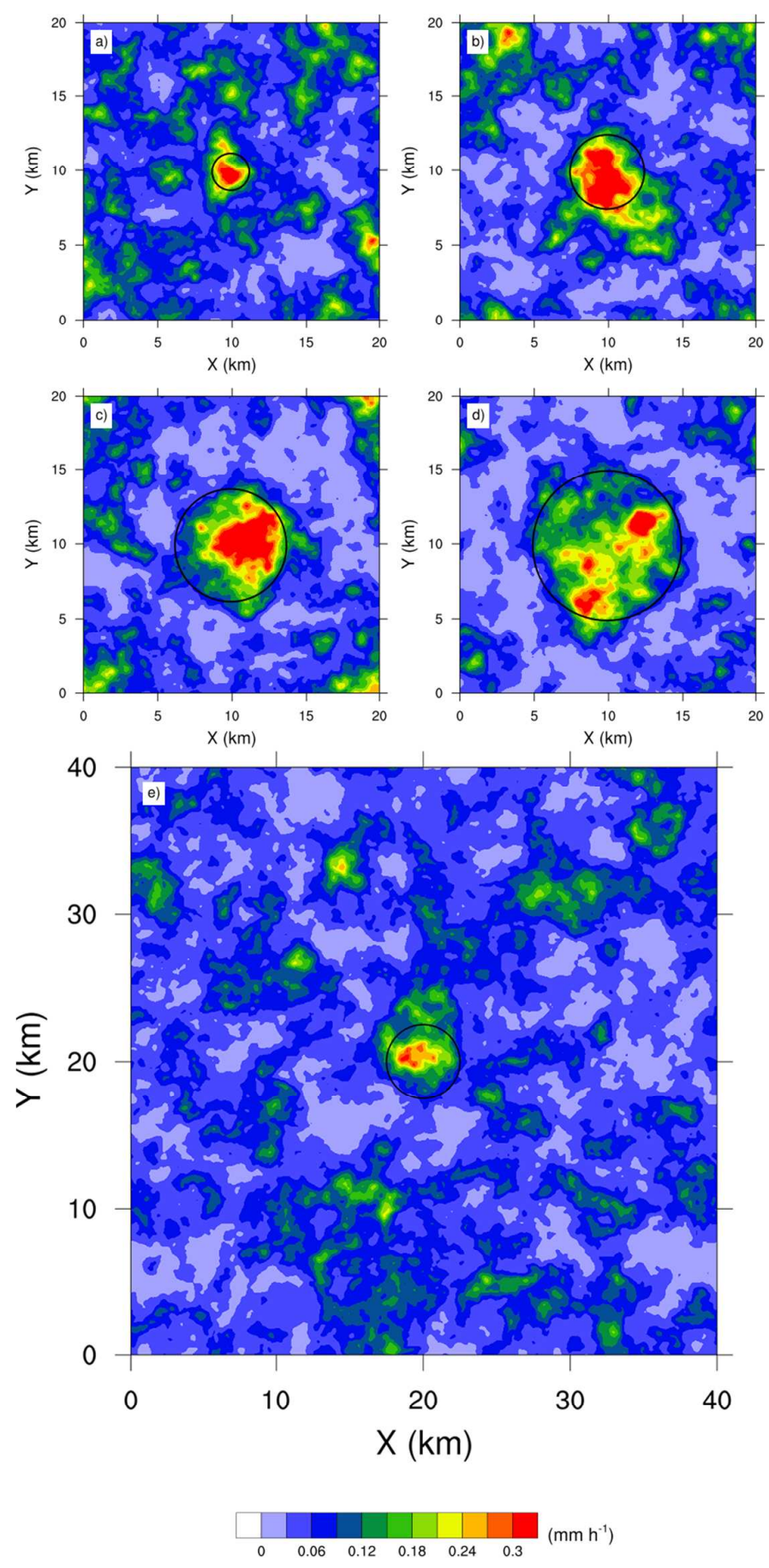

Figure 13. Same as Fig. 10 but for (a) case D2.5; (b) case D5; (c) case D7.5 (d) case D10 (e) case D5L 

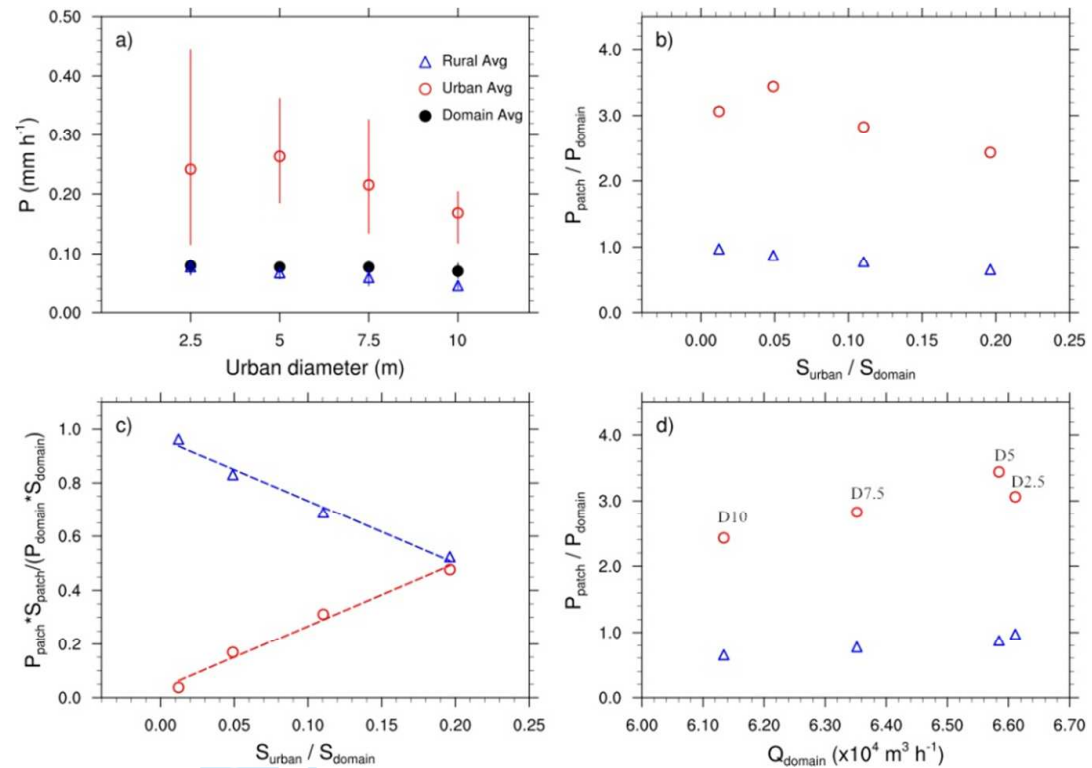

Figure 14. (a), (b) and (c) are same as Fig. 11 but for cases within different urban diameters in the domain. (d) is the relationship between the normalized rainfall rates and the total water supply from land. 


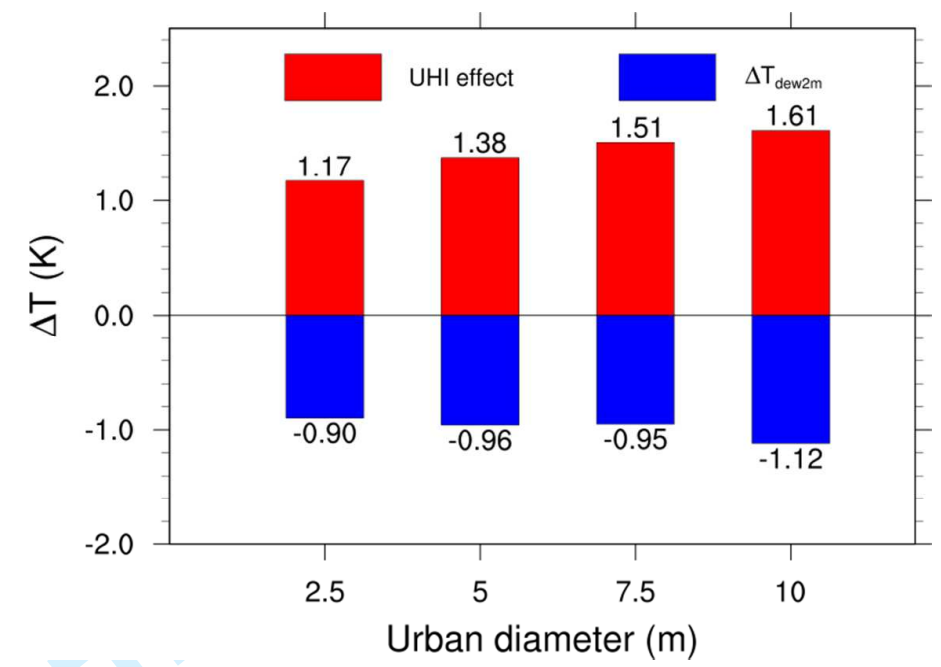

Figure 15. Same as Fig. 12 but for cases within different urban diameters in the domain. 

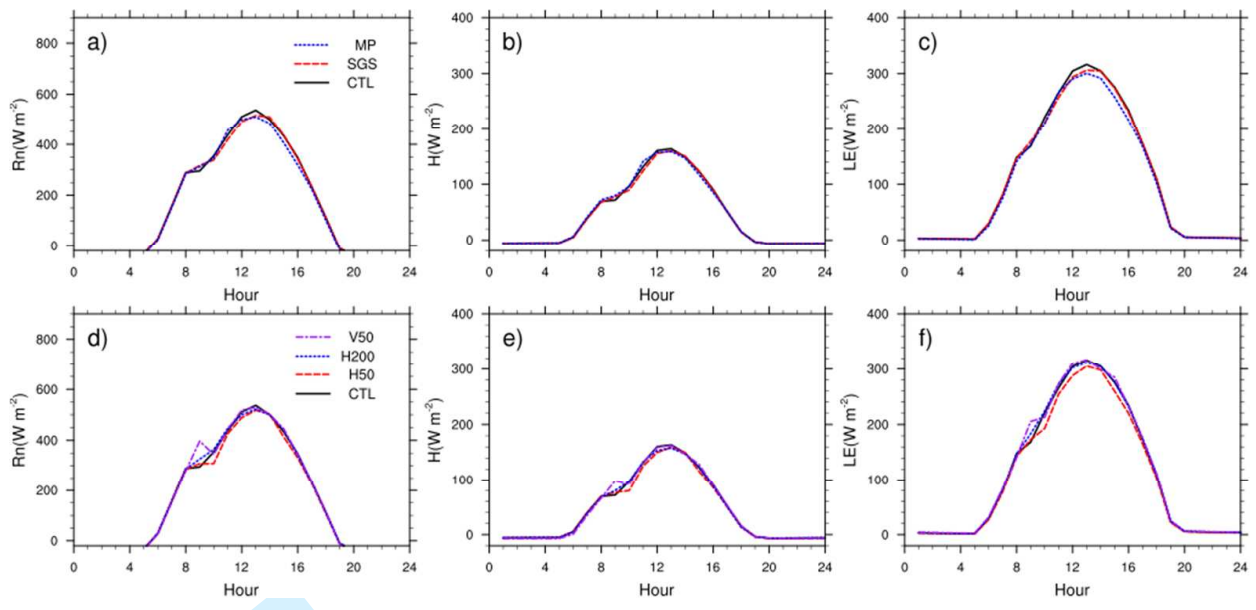

Figure A1. The average diurnal cycle of (a, d) surface net radiation $(\mathrm{Rn}),(\mathrm{b}, \mathrm{e})$ surface sensible heat flux $(\mathrm{H})$ and $(\mathrm{c}, \mathrm{f})$ surface latent heat flux (LE) 

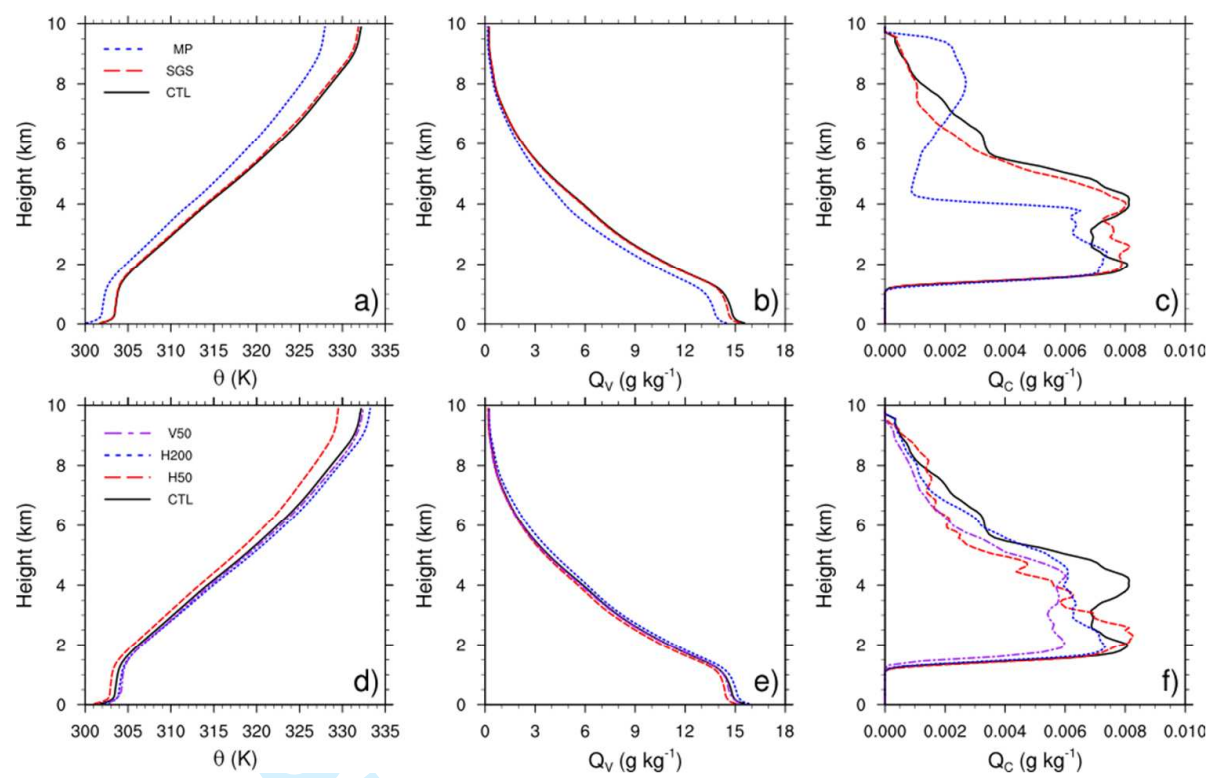

Figure A2. Vertical profiles of domain averaged $(\mathrm{a}, \mathrm{d})$ potential temperature $(\mathrm{K})$, (b, e) water vapor mixing ratio $\left(\mathrm{g} \mathrm{kg}^{-1}\right)$, and (c, f) cloud water mixing ratio $\left(\mathrm{g} \mathrm{kg}^{-1}\right)$. 

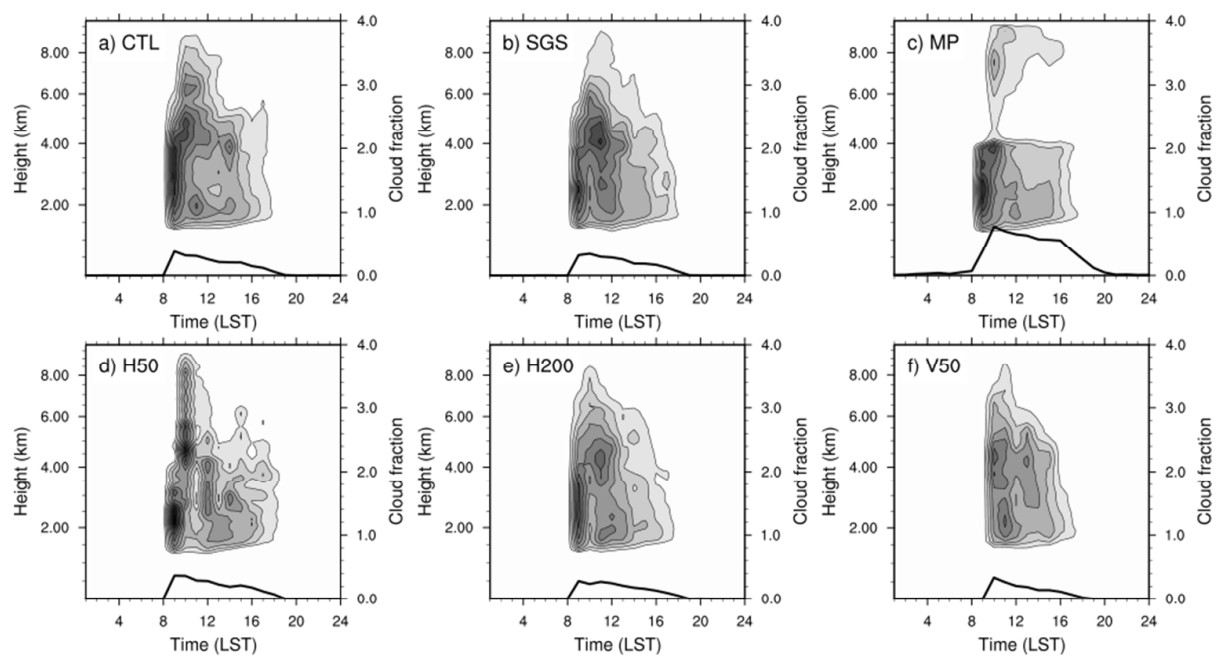

$\begin{array}{llllllllll}0.005 & 0.01 & 0.015 & 0.02 & 0.025 & 0.03 & 0.035 & 0.04 & 0.045 & 0.05\end{array}$

$\left(\mathrm{g} \mathrm{kg}^{-1}\right)$

Figure A3. The diurnal cycle of cloud water mixing ratio ( $\mathrm{g} \mathrm{kg}^{-1}$, shaded area) and cloud cover fraction (solid black line). The (a), (b), (c), (d), (e) and (f) are results of the case CTL, SGS, MP, H50, H200 and V50, respectively. Note that the y-axis is not equidistant as the WRF model uses eta levels in the vertical direction. 

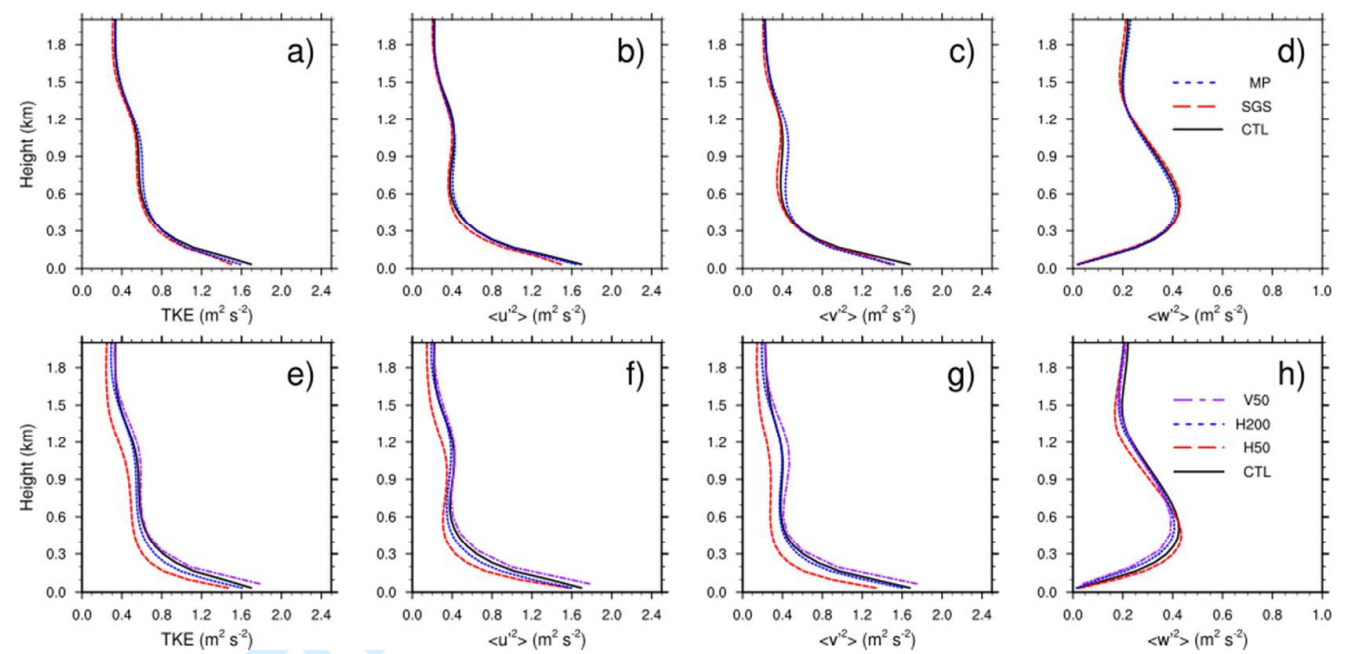

Figure A4. Vertical profiles of TKE and its three components: (a, e) TKE; (b, f)

$<\boldsymbol{u}^{\prime} \boldsymbol{u}^{\prime}>$; (c, g) $<\boldsymbol{v}^{\prime} \boldsymbol{v}^{\prime}>$; (d, h) $<\boldsymbol{w}^{\prime} \boldsymbol{w}^{\prime}>$. The top row compares cases MP, SGS and CTL, while the bottom row shows cases V50, H200, H50 and CTL. 

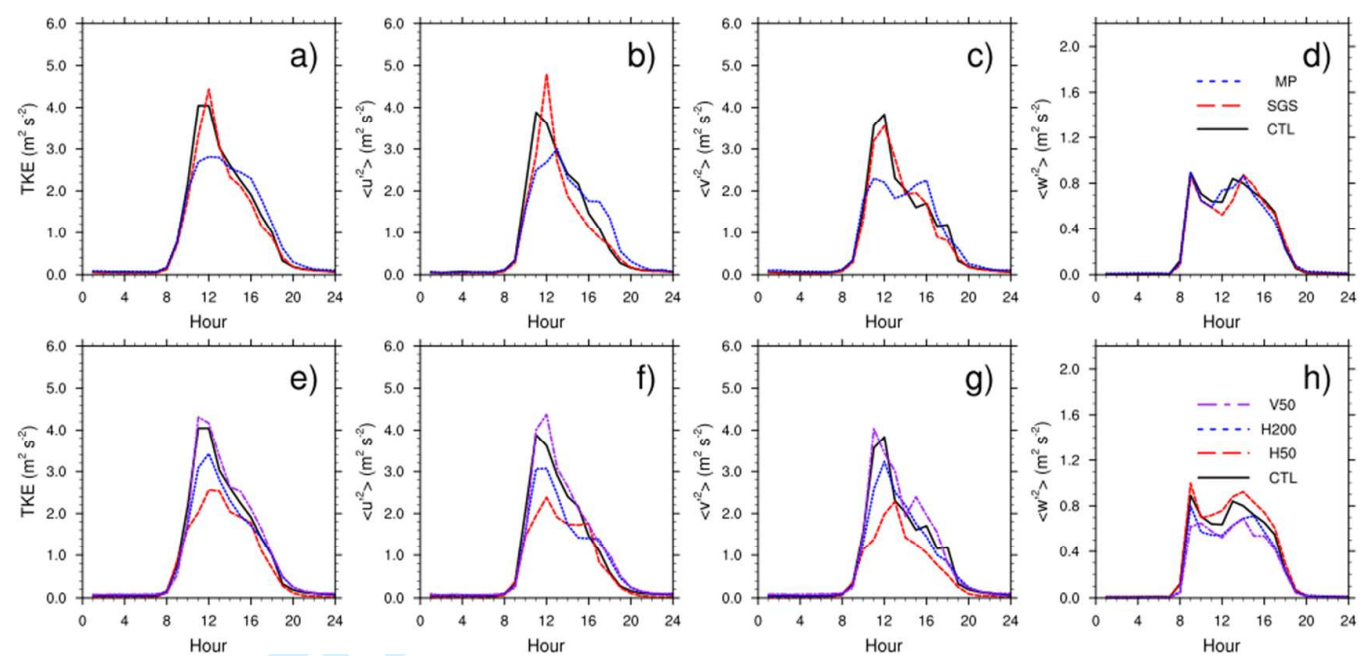

Figure A5. Same as Fig. A4 but for the average diurnal cycle of TKE and its three components at a height of $200 \mathrm{~m}$. 
1

2

3

4

5

6

7

8

9

10

11

12

13

14

15

16

17

18

19

20

21

22

23

24

25

26

27

28

29

30

31

32

33

34

35

36

37

38

39

40

41

42

43

44

45

46

47

48

49

50

51

52

53

54

55

56

57

58

59

60

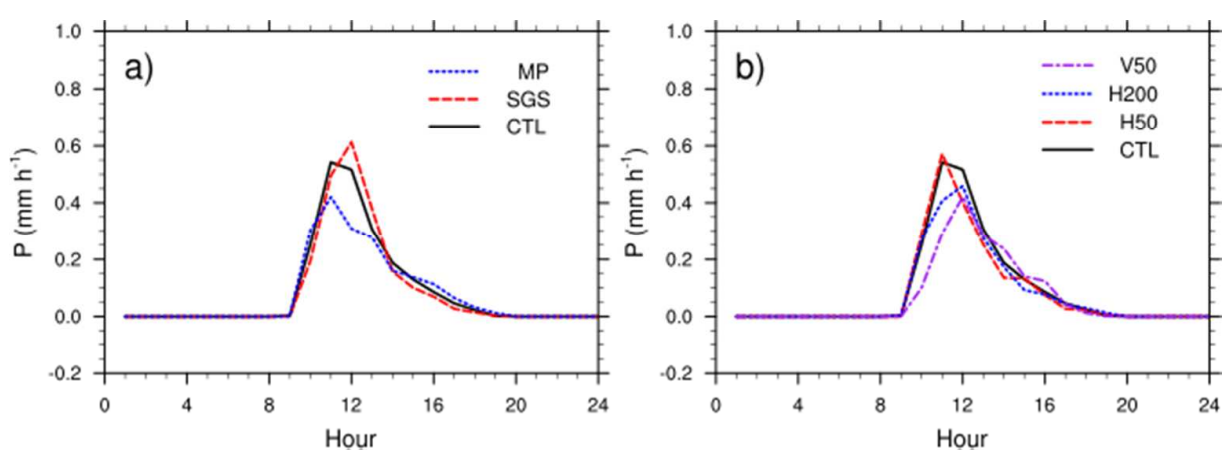

Figure A6. The average diurnal cycle of surface precipitation rate $\mathrm{P}\left(\mathrm{mm} \mathrm{h}^{-1}\right)$. 